\title{
LA ESCUELA INDUSTRIAL Y DE ARTES Y OFICIOS DE LOGROÑO
}

\author{
Isabel MARTÍNEZ NAVAS \\ PROFESORA TITUlar DE Historia DEL DERECHO Y DE LAS INSTITUCIONES \\ UNIVERSIDAD DE LA RIOJA
}

SuMARIo: Introducción. I. La Escuela Industrial y de Artes y Oficios de Logroño (I9II-I924). I. La reforma de las enseñanzas industriales en I9I0. 2. Establecimiento de la Escuela y primeros pasos. 3. Implantación de las nuevas enseñanzas. El curso I9I2-13. 4. Estructura y funcionamiento de la Escuela. II. El reglamento interior de I9I2. III. Relación del personal docente, administrativo y de servicios, matrícula de la Escuela Industrial y cuadro de las enseñanzas. IV. Reglamento de Régimen Interior de la Escuela Industrial y de Artes y Oficios de Logroño.

RESUMEN: La historia de la formación profesional en la provincia de Logroño está aún por hacer. El presente estudio supone una primera aproximación en la que se centra la atención en el período comprendido entre I9I0 y I924, esto es, en los años en que inicia su actividad la nueva Escuela Industrial, implantándose las enseñanzas de peritaje industrial y mecánico.

PALABRAS CLAVE: Formación profesional, Escuela Industrial, Artes y Oficios.

ABSTRACT: The history of professional training in the province of Logroño is yet to do. This study represents a first approach where the focus is on the period between I9IO and I924, that is, in the years in which starts its new Industrial School activities, implementing the teachings of industrial and mechanical expertise.

KEYWORDS: Professional training, Industrial School, School of Artes y Oficios.

\section{Introducción}

El estudio de las enseñanzas profesionales ha comenzado a reclamar la atención de los especialistas hace poco tiempo. En los últimos años, un buen número de publicaciones han ido acercándonos algunas de las Escuelas de Artes y Oficios establecidas en diferentes localidades, prestándose atención principalmente al período fundacional de estos centros educativos. Junto a estos estudios particulares, más recientemente, han visto la luz otros en los que la atención se centra en la evolución de las enseñanzas profesionales en su conjunto, traspasándose además las fronteras temporales más habituales entre los primeros e instalándose de lleno en el siglo XX. Entre estos últimos, son mayoritarios los que atienden a la evolución de la formación profesional en la segunda mitad del siglo, y, para el período anterior, los que se centran en la que puede considerarse como la etapa de 
consolidación de la formación profesional, esto es, la inaugurada con el Estatuto de las Enseñanzas Industriales y el Estatuto de la Formación Profesional, a partir de I924. Las diferentes aportaciones han permitido que, poco a poco, vaya abriéndose el camino sobre un terreno que se me antoja aún difícil de aprehender, en el que es preciso escrutar no solo la actividad de las diferentes administraciones, sino también la del propio sector privado y en el que, como es sabido, juegan también un relevante papel algunas instituciones religiosas ${ }^{\mathrm{I}}$.

El estado de la cuestión en torno a la historia de la formación profesional en La Rioja no es demasiado alentador. A diferencia de otras provincias -en las que, como antes apunté, se cuenta desde hace tiempo con estudios detenidos de la evolución de sus respectivas Escuelas de Artes y Oficios en el último tercio del siglo XIX-, la historia de la Escuela de Artes y Oficios de Logroño está aún por hacer. La publicación en I986 de un libro conmemorativo del centenario de su creación permitió llevar a cabo diferentes aproximaciones que, en lo que aquí interesa, incidieron sobre los precedentes y su establecimiento a finales de $1886^{2}$. Queda, sin duda, camino por recorrer. Es importante abordar la pequeña historia de este centro educativo, pero sobre todo resulta necesario reconstruir la evolución de las enseñanzas profesionales en La Rioja, prestando así atención a los diferentes centros que sucesivamente fueron encargándose de las mismas hasta la promulgación de la Ley de 20 de julio de I955, sobre Formación Profesional Industrial.

En las siguientes páginas me propongo una primera aproximación a la Escuela Industrial y de Artes y Oficios de Logroño, esto es, al centro de enseñanza profesional a través del cual se canaliza la oferta educativa profesional, de nivel elemental y medio, entre los años I9I2 y I925. La elección de este período no es caprichosa. Un rápido repaso a las publicaciones en torno a la enseñanza profesional en la provincia de Logroño, pone de manifiesto que son conocidos, como antes dije, el origen y primeros años de actividad de la

${ }^{\text {I }}$ Sin ánimo de exhaustividad y referidas tan sólo a los estudios generales acerca de la Formación Profesional en Europa, pueden citarse, CANO PAVON, J.M., «La Enseñanza Técnica en España y en Europa Occidental y el problema de la formación del capital humano industrial: veinticinco años de estudios», en Llul: Revista de la Sociedad Española de Historia de las Ciencias y de las Técnicas, vol. 26, núm. 56, 2003, pp. 367-398; CHARLOT, B. y FIGEAT, M., Histoire de la formation des ouvriers: 1789-1984, París, I985; DURÂN RODRÍGUEZ, M.D., «La educación técnica popular en Francia y España (I780-I950): algunas consideraciones acerca de las escuelas de artes y oficios en ambos países», en Sarmiento, I3, 2009, pp. 69-99; ESCOLANO, A., «La academización de la educación técnica a fines del Antiguo Régimen», en Historia de la Educación, I7, I988, pp. 33-5I y «Economía e Ilustración. El origen de la escuela técnica moderna en España», en Historia de la Educación, I, I982, pp. I62I9I; FERNÁNDEZ DE PEDRO, S. y GONZÁLEZ DE LAFUENTE, A., «Apuntes para una historia de la Formación Profesional», en Revista de Educación, núm. 239, julio-agosto I985; GREINERT, W., «Mass vocational education and training in Europe. Classical models of the Iوth century and training in England, France and Germany during the first half of the 20th», en Cedepof Panorama Series, II8, 2005 ; LOZANO LÓPEZ DE MEDRANO, C. «Los modelos de educación técnica entre I800-I9I4: Europa y los Estados Unidos», en Actes de la VII Trobada d'història de la ciencia $i$ de la técnica, Barcelona, 2003; MADARIAGA, C. de, La formación profesional de los trabajores, Madrid, I933 y La educación del obrero. Estudio de un esquema normal de formación del obrero, Madrid, I92I; MALLART Y CUTÓ, J., La formación profesional en España, Madrid, I933, La organización de la formación profesional en España, Madrid, I92I, «El concepto de Escuela del Trabajo», en Revista de Pedagogía, año VII (I928), pp. 408-4I4; NOVO DE MIGUEL, L., La enseñanza profesional obrera $y$ técnico industrial en España, Madrid, I933; RICO GÓMEZ, M.L., «La formación profesional y las clases medias técnicas en España (I924-I93I)», en Hispania, vol. LXXII, num. 240, enero-abril (20I2), pp. II5-I22, «La formación profesional como mecanismo de transformación socio-económica (I924-I936)», en I Congreso Interuniversitario de Historia Contemporánea, Barcelona, 9-II de junio de 20I0; RODRÍGUEZ HERRERO, J.J., Formación profesional y desarrollo (1930-1970): teoría y práctica, Salamanca, I986; SEAGE, J., ORGANEL, G., QUINTANA, D., BLAS, P y GÓMEZ, A., «La enseñanza profesional en Europa (Francia, Gran Bretaña, Italia y Suecia)», en Revista de Educación, 239, pp. 5-80.

2 Primer centenario de la Escuela de Artes Aplicadas y Oficios Artísticos (1886-1986). Edición conmemorativa, Logroño, I986. 
Escuela de Artes y Oficios de Logroño, en tanto se ha prestado escasa y desigual atención porque ha interesado fundamentalmente la historia más reciente- a la historia de la formación profesional en la provincia a lo largo del siglo $\mathrm{XX}^{3}$. Un estudio reciente parece venir a paliar ese déficit de interés del que hablo, abordando el estudio del origen y estado actual de la formación profesional en La Rioja ${ }^{4}$. A lo largo de sus páginas vamos viendo aparecer algunos de los centros en los que se impartieron estas enseñanzas profesionales en La Rioja hasta la mitad del siglo XX. Entre ellos, la Escuela Industrial y de Artes y Oficios de Logroño merece un capítulo independiente en el que se ofrece un rápido recorrido desde los primeros atisbos de enseñanzas profesionales en la provincia, allá por la mitad del siglo XIX, hasta la promulgación de la Ley de Formación Profesional antes mencionada.

La escasa atención prestada hasta ahora a la Escuela Industrial instalada en Logroño obedece, sin duda, a lo limitado de las fuentes documentales conservadas en el archivo de la actual Escuela de Arte y Diseño. La principal laguna se refiere precisamente a este período, de suerte que junto a la escasa documentación conservada en el Archivo Histórico Provincial de La Rioja, me he servido también de algunas noticias localizadas en el Archivo General de la Administración, en el Municipal de Logroño y en el Archivo General de la Universidad de La Rioja. Con todo, la mayor parte de los datos recuperados provienen de las memorias académicas elaboradas anualmente por la propia institución.

El estudio que me planteo es, consecuentemente, limitado. En la primera parte, efectúo un breve repaso de la génesis de la nueva Escuela Industrial y su evolución hasta I924 en el marco de un centro que acoge también aún las enseñanzas artístico-industriales. En la segunda, me refiero al reglamento de régimen interior aprobado por el claustro de profesores de la Escuela en septiembre de I9I2. Un reglamento del que solo conozco un ejemplar no impreso, con anotaciones manuscritas y la rúbrica del equipo directivo de la Escuela. Un texto del que interesan aquí tan solo sus aspectos formales, de técnica normativa, y cuyo estudio pormenorizado excede las pretensiones de esta primera aproximación a los orígenes de las enseñanzas profesionales en La Rioja ${ }^{5}$.

\footnotetext{
${ }^{3}$ Se ha prestado atención a las enseñanzas profesionales en La Rioja en los diferentes trabajos de carácter general sobre la Educación en la provincia en el siglo XIX. Así, se refieren al inicio de la actividad de la Escuela de Artes y Oficios, a partir de I879, tanto BUISINE-SUBIROUX, M. H., Albafetización, Educación y Sociedad en Logroño en tiempos de Espartero (1833-1875), como RUIZ RIVAS, F., Análisis histórico de las instituciones $y$ realizaciones socioeducativas del ayuntamiento Logroño desde la ley Moyano hasta la ley Villar Palasí (1857-1970), Tesis doctoral, Logroño, I999. Asimismo, por lo que se refiere al último tercio del siglo XIX, ECHEVARRÍA, L., «La Educación Secundaria en La Rioja (en la Restauración)», en Berceo, I2I, I99I, pp. I03-I22, presta atención brevemente a la Escuela de Artes y Oficios de Logroño. Sobre la misma, véanse también las referencias incluidas en BENITO, J.J., Las Escuelas Estatales de Artes y Oficios y la Educación del Obrero en España (1871-1900), Madrid, 2002.

${ }^{4}$ La revista Berceo ha dedicado el número $\mathrm{I}_{5}$, correspondiente a 20I3, a un estudio monográfico sobre la Educación en La Rioja. Entre los trabajos publicados interesa aquí especialmente el de ZAPATER CORNEJO, M., «La Educación profesional en La Rioja. Origen y situación actual», pp. I25-I49.

${ }^{5}$ Me he ocupado de otros aspectos, tales como el establecimiento de las Escuelas del Trabajo de Logroño y de Haro a partir de 1924, con ocasión del Congreso Historia de la Educación Media y Superior en el valle del Ebro: el distrito universitario de Zaragoza (siglos XIX-XX), celebrado en Logroño el 2I y 22 de noviembre de este año. Asimismo, estoy elaborando en la actualidad un estudio de la Escuela de Artes y Oficios de Logroño entre I886 y I924.
} 


\section{La Escuela Industrial y de Artes y Oficios de Logroño (I9II-I924)}

En Logroño habría funcionado una Escuela de Artes y Oficios desde finales de I879. Sostenida por el Ayuntamiento de la ciudad, su trayectoria no es bien conocida ${ }^{6}$. A partir de ı886, la capital riojana será la sede de una de las siete escuelas estatales establecidas por real decreto de 5 de noviembre 7 . La Escuela de Artes y Oficios de Logroño iniciará su actividad en el curso i887-88 con un modesto cuadro de enseñanzas: Aritmética, Geometría y principios del arte de la construcción, Nociones de física, química y mecánica, Dibujo geométrico industrial, con instrumentos y a mano alzada, Dibujo de adorno y de figura con aplicaciones de colorido a la ornamentación y Modelado y vaciado ${ }^{8}$. La Escuela de Artes y Oficios de Logroño, que habría mantenido unas cifras estables de matrícula desde su creación, da paso, en el comienzo del siglo XX a la nueva Escuela de Artes e Industrias, resultante de la reorganización de las enseñanzas artísticas e industriales acometida en enero de i900. A Logroño le correspondió en ese momento -a diferencia de lo que ocurrió con la mayor parte de las otras escuelas estatales creadas en I886- una Escuela Elemental de Artes e Industrias, constituyéndose en el único centro de enseñanza profesional en la provincia hasta I9IO.

\section{I.I. La reforma de las enseñanzas industriales en I9ıO}

El curso I9Io-II comenzaba plagado de incertidumbres. Unos meses antes -en junio de I9ıо- se había alterado sustancialmente la organización de las Escuelas de Artes e Industrias.

«La instrucción y la educación de los obreros -recordará el Ministro de Instrucción Pública- y la necesidad de orientar la juventud española hacia el cultivo de las profesiones técnicas, vienen siendo con sobrada razón, motivo de meditaciones constantes para los Gobiernos de V.M., que, inspirándose siempre en los más elevados intereses del país, han dedicado para ello preferente atención al régimen de las antiguas Escuelas de Artes y Oficios, transformadas después en Escuelas de Artes y de Industrias, con muy variadas denominaciones.

Las reformas que ese interés y esas meditaciones han producido, muy bien intencionados siempre, no han dado, por desgracia, los favorables resultados que sus autores esperaban de ellas»?

La reforma se enmarcaba en la más ambiciosa revisión de las enseñanzas medias alentada por el conde de Romanones ${ }^{\mathrm{Io}}$. Por lo que se refiere a las enseñanzas técnicas, el

\footnotetext{
${ }^{6}$ RUIZ RIVAS, F., Análisis histórico de las instituciones..., cit. pp. 585-624. Incluye en el texto y en el correspondiente apéndice documental transcripciones de diferentes acuerdos del Ayuntamiento de Logroño e informes emitidos por otras instituciones, que permiten recrear los sucesivos intentos de establecimiento de una Escuela de Artes en Logroño desde i855 y de manera especial la tramitación del expediente que condujo al establecimiento de una Escuela municipal de Artes y Oficios en la capital riojana en I879.

${ }^{7}$ Junto al ya citado estudio de conjunto de BENITO, J.J., Las Escuelas Estatales de Artes y Oficios..., son muy numerosas las publicaciones que atienden con carácter particular a las Escuelas de Artes y Oficios establecidas en diferentes localidades: Alcoy, Béjar, Santiago, Zaragoza, etc.

${ }^{8}$ Archivo Histórico Provincial (La Rioja) (en adelante AHPLR), Escuela de Arte y Diseño (en adelante, EAD), leg. 138 .

${ }^{9}$ Real decreto de 8 de junio de ı9ıo, en Colección legislativa de Instrucción Pública, añoıgıo, pp. 274-290.
} 
ministro, amparándose en las estadísticas oficiales, llamaba la atención sobre la escasa eficacia de las denominadas Escuelas de Artes y Oficios o Escuelas de Artes e Industrias -a las que se había encomendado la instrucción técnica elemental de los obreros- y sobre la merma de la vis atractiva de las Escuelas Superiores Industriales, cuya matrícula disminuía cada año.

«Las estadísticas oficiales, formadas por las Escuelas mismas, demuestran que la eficacia de la enseñanza en ese grado no es, ni muchísimo menos, la que todos desearíamos. Una inmensa mayoría -que en algunas Escuelas es casi la totalidad- de los obreros matriculados en ellas pierden curso, siendo así inutilizados los afanes con que, tras una fatigosa jornada de trabajo, emplearon las primeras horas de la noche en buscar, mediante el estudio, mejoramiento de su condición social; y, por otra parte, la matrícula en las enseñanzas técnicas, lejos de aumentar, disminuye de año en año, malográndose así, por diferentes y variadas causas, los buenos propósitos de los legisladores»"

La búsqueda de mayor acierto en la organización de los centros encargados de las enseñanzas profesionales se canalizó así a través del decreto de 8 de junio de i9ıo ya mencionado $^{\mathrm{T} 2}$, a tenor del cual las enseñanzas impartidas en los diferentes centros de formación profesional resultarían organizados en dos grados -elemental y superior-, correspondientes a la primera y segunda enseñanza técnica. Los estudios elementales serían impartidos en lo sucesivo en la Escuela de Artes y Oficios, en tanto los superiores lo serían en las denominadas Escuelas Industriales.

«Las Escuelas de Artes y Oficios -aclaraba el art. $\mathrm{I}^{\circ}$ in fine- tendrán por principal objeto la instrucción y educación técnica de los obreros, servirán también como preparatorias para el ingreso en las Escuelas Industriales.

Las Escuelas Industriales prepararán para los diversos peritajes, y harán las reválidas a ellos correspondientes».

El propio decreto contemplaba después -arts. 2 al 29-el curriculum de los dos tipos de escuelas técnicas, los procedimientos de acceso de sus profesores y el régimen administrativo de esos centros.

Sin embargo, la falta de previsión de un régimen transitorio que amparase la conclusión del curso i909-Io en las diferentes escuelas de Artes e Industrias y de Artes Industriales, así como la inadecuación de algunas de las previsiones relativas a cuestiones sensibles -como lo eran la provisión de puestos docentes y otros aspectos del ámbito de la ordenación académica- hizo necesario que, en los meses siguientes, fuesen dictándose una serie de disposiciones normativas que, sin duda, contribuyeron a incrementar la confusión provocada por la reforma del mes de junio.

${ }^{10}$ Sobre la reforma de I9Io, LOZANO LÓPEZ DE MEDRANO, C., Ideología, política y realidad económica en la formación profesional industrial española (1857-1936), Lleida, ed. Milenio, 2007, pp. 59-6I.

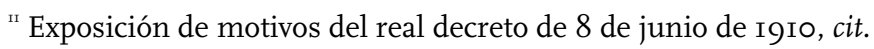

${ }^{12}$ A juicio del ministro de Instrucción Pública del Gobierno liberal de Canalejas, la necesaria reforma pasaba por adoptar un modelo de enseñanzas técnicas especializadas en atención al entorno socio-económico al que iban dirigidas. Algunas de las propuestas reformistas de Romanones en Memoria elevada a las Cortes por el Excmo. Sr. Ministro de Instrucción Pública en que expone, como antecedentes del proyecto de presupuestos para 1911, algunos datos acerca del estado actual de la enseñanza pública y los fundamentos de las reformas propuestas, Madrid, Establecimiento Tipográfico y Editorial, ı9ıo. 
Apenas dos meses después de introducida la reforma, el Gobierno se veía obligado a dejarla en suspenso ${ }^{\mathrm{I} 3}$. La razón invocada en este caso sería la imposibilidad de implementar las múltiples modificaciones que se habían previsto para las escuelas industriales en el corto espacio de tiempo que restaba hasta el inicio del curso I9Io-II, más aún cuando se carecía del adecuado desarrollo normativo ${ }^{\mathrm{T4}}$.

Un mes más tarde, sin embargo, se levantaba la suspensión, afirmándose que no era preciso aguardar al desarrollo reglamentario cuya falta había justificado la anterior decisión de suspender la aplicación del decreto que canalizaba la reforma de las enseñanzas profesionales. La justificación a la adopción de medidas contradictorias en tan corto espacio de tiempo se hacía descansar en la supuesta desaparición de los principales escollos para la puesta en marcha de la reforma. A saber, que ya había concluido el período de exámenes extraordinarios correspondientes al curso I909-Io -cuyo desarrollo no había sido previsto en el real decreto de 8 de junio- y que se habían despejado todas las dudas acerca del destino del profesorado en las nuevas Escuelas de Artes y Oficios y Escuelas Industriales ${ }^{15}$.

No obstante lo apuntado, apenas una semana después, dos nuevas disposiciones venían a alterar de nuevo el statu quo. Por una parte, se resolvía suspender -parcialmente ahora- la aplicación del decreto de junio ${ }^{\mathrm{I}}$. De otro lado, en contra de lo que se había argumentado días atrás, se desplegaban nuevas aclaraciones, que se entendían necesarias para la implantación de la reforma ${ }^{17}$. Nuevas aclaraciones referidas tanto al carácter de las enseñanzas impartidas en las nuevas Escuelas, como a la orientación y alcance de las enseñanzas reunidas bajo las rúbricas «Dibujo», uno de los puntos clave de la reforma emprendida por Romanones ${ }^{\mathrm{I}}$. Las aclaraciones alcanzaban también a las nuevas categorías

\footnotetext{
${ }^{\mathrm{r} 3}$ Real orden de 22 de agosto de I9Io, en Gaceta de Madrid del 24 de agosto.

${ }^{14}$ «Habiéndose presentado varias dificultades para poder aplicar en el próximo curso académico las disposiciones de varios artículos del Real decreto de 8 de Junio último por las múltiples modificaciones que establecen en la actual organización de las Escuelas de Artes é Industrias y de Artes Industriales y por la escasez de tiempo dado lo avanzado de este período del año, para efectuar de manera completa y acertada aquélla implantación, mucho más careciendo del Reglamento correspondiente, y teniendo en cuenta también que se irrogarían graves perjuicios no estando, en el inmediato mes de Septiembre, en el que han de celebrarse los exámenes extraordinarios debidamente ultimados los cuadros de las nuevas enseñanzas», ibídem.

${ }^{15}$ «Entre las dificultades que imponían una suspensión de los efectos consiguientes á las disposiciones del Real decreto de 8 de Junio último reorganizando los servicios en las Escuelas de Artes industriales y de Industrias, aparecía como una de las más principales lo inmediato de los segundos exámenes del curso. No había sido previsto ni menos prevenido ese momento de transición. Pero transcurrido ya y estudiadas y resueltas todas las dudas acerca del carácter de la reforma en punto á la división del personal, y no siendo imprescindible para el funcionamiento inmediato de las Escuelas de Madrid y de los demás Centros el esperar á la publicación del Reglamento, que en nada puede modificar el carácter ni el número de enseñanzas.

S.M., el Rey (q.D.g.) se ha servido disponer que desde luego sea ejecutado y aplicado el Real decreto de 8 de Junio ya citado, ajustándose la matrícula para el curso próximo á las disposiciones del mismo», Real orden de 2I de septiembre de I9ıo, en Colección legislativa de Instrucción Pública, año ı9ıo, p. 370.

${ }^{16}$ La suspensión se ceñía ahora a las previsiones del art. 23 del Real decreto de 8 de junio. Se pretendía así evitar la posible lesión de derechos adquiridos por los estudiantes que hubiesen obtenido ya, o estuviesen en condiciones de poder obtener, el título de perito en lo que se refiere al acceso, sin examen, en las Escuelas de Ingenieros Industriales, Real orden de 28 de septiembre de I9Io, ibídem, p. 375.

${ }^{17}$ Real orden de 28 de septiembre de I9ıо, en ibídem, pp. 373-374.

${ }^{18}$ A juicio del ministro de Instrucción Pública la principal causa de la falta de eficacia de las enseñanzas impartidas en las Escuelas de Artes y Oficios y de Artes e Industrias radicaba en la falta de interés por parte de los obreros «que, no viendo la aplicación inmediata de ellas y matriculándose en clases orales únicamente cuando se les imponía la matrícula como obligación ineludible, han seguido atendiendo únicamente al dibujo y considerando las Escuelas de Artes é Industrias, en sus enseñanzas generales, como Escuelas de Dibujo aplicado únicamente». Apostaba, así, por suprimir «las enseñanzas preparatorias y orales como clases ó cátedras aparte, instaurándolas como complemento de las clases de Dibujo, modo de hacer éstas más útiles y ampliar al
} 
de profesorado, al modo de provisión de las vacantes que se produjeren en adelante, a la composición de las Juntas de Profesores, a la ubicación de algunos de los talleres en cada grupo de escuelas, a la admisión y matrícula de los alumnos, o al modo en que se deberían desarrollarse las pruebas de curso ${ }^{19}$.

Entre junio y septiembre de igıo el marco legal de las enseñanzas técnicas había resultado, sin duda, especialmente confuso. Es en este contexto -con el real decreto de 8 de junio en suspenso- en el que se habría dispuesto, el 24 de agosto, la elevación a Superior de la Escuela Elemental de Artes Industriales de Logroño.

\section{I.2. Establecimiento de la Escuela Industrial y primeros pasos}

El 24 de agosto de I9ıo, evocando los resultados obtenidos por la Escuela Elemental de Artes Industriales existente en Logroño y haciéndose eco de las bondades de extender las enseñanzas impartidas en ese centro educativo a las encaminadas a formar a «obreros instruidos en los distintos aprendizajes» y «personal adornado de título y capacidad suficientes», se disponía que comenzasen a impartirse en la Escuela Superior de Artes Industriales de Logroño las nuevas enseñanzas profesionales de nivel medio.

«La Escuela Elemental de Artes Industriales de Logroño -establecía el art. I ${ }^{\circ}$ - se denominará en lo sucesivo Escuela Superior de Artes Industriales, y en ella se darán las enseñanzas que las necesidades de la región exijan, dentro de lo legislado para estos centros docentes en el Real decreto y Reglamento de 6 de agosto de I907» ${ }^{\circ}$.

El propio decreto fijaba la plantilla docente, administrativa y de servicios de la Escuela y garantizaba su dotación y la destinada a gastos de personal con cargo a la debida consignación de crédito en el proyecto de Ley de Presupuestos del año I9II. La nueva Escuela Superior de Artes Industriales debía contar con seis profesores numerarios, dos auxiliares numerarios y dos ayudantes repetidores, junto a los que un maestro y un ayudante asumirían la coordinación de los talleres. La nueva plantilla suponía, tan sólo, el incremento de un profesor numerario con respecto a la existente en la Escuela de Artes e Industrias de Logroño ${ }^{21}$.

La elevación a Superior de la Escuela ponía punto final a una vieja reivindicación del claustro de la Escuela de Artes e Industrias y del Ayuntamiento de Logroño, disipándose el agravio que pareció representar la no inclusión de Logroño entre las localidades en las que fueron creadas escuelas superiores diez años antes ${ }^{22}$.

mismo tiempo la primera enseñanza, hasta darle en los últimos grados, mediante explicaciones de mecánica y construcción muy elementales, un determinado carácter elementalmente profesional», Real decreto de 8 de junio de I9Io, cit.

${ }^{19}$ Real orden de 28 de septiembre de I9ıо, en Colección legislativa de Instrucción Pública, pp. 373-374.

${ }^{20}$ Real decreto de 24 de agosto de iوıo, en ibídem, pp. 33i-332.

${ }^{21}$ Sobre esta última, véase AHPLR, EAD, leg. 146/2.

${ }^{22}$ Ibídem, Minuta de los acuerdos adoptados en la sesión de la Junta de Profesores de la Escuela de Artes e Industrias de 3 de abril de I902. Sobre las diferentes gestiones realizadas por el Ayuntamiento de la ciudad a partir de ese tiempo, Archivo Municipal de Logroño, Educación, caja 2i6, exp. 37 y los registros de las actas correspondientes a las sesiones celebradas por la corporación municipal el 29 de marzo y el 3 de mayo de I902. 
Así las cosas, no resultan extrañas las palabras con las que el director de la Escuela logroñesa se dirige a los asistentes a la inauguración del curso igı-ı-. Habla Pérez Ordoyo de las «circunstancias especialísimas» por las que atraviesa la Escuela, «elevada a Superior, pero sin los créditos necesarios para su funcionamiento como tal» y se refiere, asimismo, a la incertidumbre acerca del alcance de las recientes reformas introducidas en la organización de las escuelas industriales. Su discurso -también las palabras pronunciadas por el secretario de la Escuela al presentar los datos estadísticos del curso anterior- reflejan, qué duda cabe, la situación de desconcierto con la que todos afrontaban el inicio del curso I9Io-II, el primero en el que la Escuela de Logroño tenía la consideración de escuela superior $^{23}$.

Las principales dudas generadas con la puesta en marcha de las medidas de reforma de las enseñanzas industriales no resultaron, de hecho, despejadas hasta finalizar el año. Sendos decretos de 16 de diciembre de I9Io vinieron a dejar definitivamente sentada la nueva organización de las enseñanzas profesionales y la de los centros educativos en que debían impartirse ${ }^{24}$. El nuevo ministro de Instrucción Pública se cuidó en aclarar que el nuevo decreto no suponía una reforma del anterior, sino tan solo un «simple ajuste y lima para el mejor encaje de la organización» introducida en el mes de junio. La nueva disposición venía, pues, a aclarar algunos extremos, inspirándose, no obstante, en los mismos criterios pedagógicos que estaban detrás de la reforma promovida meses atrás por Romanones.

La nueva regulación preveía la convivencia en delante de dos grupos de escuelas las Escuelas de Artes y Oficios y las Escuelas Industriales- que, en algunos casos, entre los que se encuentra la Escuela de Logroño, continuarán compartiendo, a lo largo del período aquí analizado, no solo unas mismas dependencias, sino también una única Dirección, un mismo claustro, Secretaría y personal administrativo y subalterno. La no separación en este tiempo de las dos nuevas escuelas daba satisfacción a los deseos expresados por el equipo directivo riojano en el comienzo del curso, en un momento en el que el alcance de la reforma que se pretendía introducir y, por ende, la existencia misma de la propia Escuela resultaban difíciles de predecir. Señalaban entonces, aduciendo el carácter especial de su centro, que sería aconsejable que se mantuviesen ambas escuelas unidas, como en efecto sucedió. Así, aun cuando merced a la nueva estructura de enseñanzas y centros se entenderá establecida una nueva escuela a la que se encomiendan las enseñanzas de perito mecánico y perito electricista, el nuevo centro quedará subsumido en la más amplia escuela mixta o de doble carácter, industrial y de artes y oficios, no registrándose el desdoblamiento efectivo hasta el mes de marzo de $1924^{25}$.

${ }^{23}$ Dirá así, entre otras cosas, que está perplejo al asumir su obligación de presentar la memoria correspondiente al año anterior, declinando expresamente su cumplimiento en lo que se refiere a la propuesta de mejoras a la vista del inmediato cambio de escenario para las enseñanzas profesionales, Escuela de Artes Industriales de Logroño. Sesión pública celebrada el día 16 de octubre de 1910 para repartir los premios a los alumnos de esta Escuela. Memoria correspondiente al curso de 1909 a 1910, Imprenta y Librería Moderna, Logroño, I9ıo.

${ }^{24}$ Real decreto y Reglamento orgánico para las Escuelas industriales y las de Artes y Oficios de i6 de diciembre de ıوıo, Gaceta de Madrid de 28 de diciembre.

${ }^{25}$ En la práctica la separación se produjo a partir de 30 de junio de ese año, tal como queda reflejado en el acta de la sesión de instalación de la Junta Inspectora de la Escuela Industrial de Logroño celebrada en I925, en Archivo General de la Universidad de La Rioja (en adelante, AUR), Libro de Actas de la Junta Inspectora de la Escuela Industrial de Logroño, 1924-1925. 
La Escuela Industrial de Logroño no pudo iniciar su actividad como centro de enseñanza profesional de grado medio en el curso i9II-I2. Tampoco fue posible que lo hiciera en el siguiente. La demora en la puesta en marcha de las nuevas enseñanzas -de la que se lamentará el director Pérez Ordoyo en el acto solemne de inauguración del curso ${ }^{26}$ se debía, de nuevo, a la falta de previsión por parte del Gobierno, que no fijará hasta avanzado el mes de octubre de I9ıI las enseñanzas que deberían impartirse en adelante en cada una de las Escuelas y la plantilla de personal docente con la que debería contar cada escuela para afrontar con éxito el desarrollo de su oferta educativa.

En efecto, el decreto de ig de octubre de I9II, dispuso que en la Escuela Industrial y de Artes y Oficios de Logroño se impartiesen los Peritajes de mecánicos y electricistas y las enseñanzas generales de Artes y Oficios ${ }^{27}$. De este modo, en el curso I9II-I2, la Escuela mantuvo su tradicional oferta de enseñanzas generales de Artes y Oficios, al tiempo que iban dándose los primeros pasos tendentes a dotar al centro de los instrumentos y locales necesarios para la puesta en marcha de las enseñanzas de peritos.

Junto a los recursos materiales precisos -para los que lamentarán la escasa dotación presupuestaria- será necesario atender también a la configuración de una plantilla docente ajustada a las previsiones del real decreto de ig de octubre, esto es una veintena de profesores pertenecientes a los cuerpos de profesores de término, de ascenso y de entrada ${ }^{28}$. Para ello, junto al profesorado al servicio de la anterior Escuela de Artes e Industrias cuatro profesores numerarios, un auxiliar y un ayudante meritorio-, la Dirección de la Escuela, de acuerdo con la Junta de Profesores, procedió en el mes de marzo al nombramiento de un buen número de ayudantes meritorios, configurando así una plantilla provisional que sería posteriormente aprobada en el marco del proceso de adaptación del personal de estos centros educativos previsto en el mencionado decreto de octubre del año anterior. Para completar el cuadro docente, pocos días antes de la inauguración del curso I9I2-I3 se dispuso que el jefe de mecánicos de la Fábrica de Tabacos de Logroño se encargase provisionalmente de la dirección de las prácticas de taller que habrían de realizar los primeros alumnos de los peritajes ${ }^{29}$.

I.3. Implantación de las nuevas enseñanzas. El curso I9I2-I3.

Así las cosas, el curso I9I2-I3 será el primero en el que la Escuela Industrial y de Artes y Oficios de Logroño impartirá las nuevas enseñanzas de perito mecánico y perito electricista, manteniendo además la oferta de enseñanzas generales impartidas en la

\footnotetext{
${ }^{26}$ Recordará en este sentido Pérez Ordoyo que por la Dirección de la Escuela se había dado puntual cumplimiento a su obligación de remitir una propuesta informada de las enseñanzas de perito que se impartirían en la Escuela y que, sin embargo, la Memoria, remitida en el mes de mayo, no había merecido respuesta alguna de la Superioridad, Escuela Industrial y de Artes y Oficios. Memoria reglamentaria y estadística del curso de 1911 a 1912, Imprenta y Librería Moderna, Logroño, I9I2.

${ }^{27}$ Gaceta de Madrid de 20 de octubre de i9iı.

${ }^{28}$ La Escuela Industrial y de Artes y Oficios de Logroño contaría con doce profesores de término, cinco profesores de ascenso y cuatro profesores de entrada, correspondiendo a estos dos grupos auxiliar a los profesores de término, art. $9^{\circ}$ del Real decreto de I9 de octubre de I9II, Gaceta de Madrid de 20 de octubre.

${ }^{29}$ Memoria reglamentaria y estadística del curso de 1911 a 1912, pp. 7-Io. En la relación de personal docente que incluyo al final, van señaladas con * los profesores que conformaron la primera plantilla de la nueva Escuela Industrial y de Artes y Oficios en el año I9I2-I3.
} 
sección de Artes y Oficios, e incorporando asimismo los cursos de preparación e ingreso en la sección Industrial.

A tenor del cuadro de enseñanzas incluido en la Memoria del curso, se impartieron en la Sección industrial el curso preparatorio -aritmética y geometría prácticas y nociones de ciencias físicas, químicas y naturales-, y las asignaturas de aritmética y álgebra, geometría plana y del espacio, geometría industrial, francés y dibujo geométrico, correspondientes al primer grupo; las de trigonometría y topografía, ampliación de matemáticas, mecánica general, física general, francés y dibujo geométrico, del segundo grupo; las de geometría descriptiva, mecánica aplicada, termotecnia, química general, prácticas de termotecnia y química, dibujo industrial, magnetismo y electricidad, correspondientes al tercer grupo; y las de mecanismos y máquinas herramientas, motores, economía y legislación industrial, dibujo industrial, prácticas de taller, electroquímica, electrotecnia y prácticas de electroquímica, del cuarto grupo. Además, en los tres primeros grupos se desarrollarían las correspondientes conferencias y prácticas de taller. Por su parte, en la Sección artística se mantuvo la tradicional oferta de gramática castellana y caligrafía, aritmética y geometría prácticas, elementos de construcción, elementos de mecánica, física y química, dibujo lineal, dibujo artístico, modelado y vaciado y elementos de historia del arte $^{30}$.

El curso concluía con un cambio en la Dirección. Habiéndose admitido, en el verano de I9I3, la dimisión presentada meses atrás por Manuel Pérez Ordoyo, en el mes de septiembre el que había sido primer director de la Escuela daba el relevo a Rafael Gutiérrez de León, quien se mantendría al frente de la misma en lo que resta del período aquí analizado.

La gestión de Pérez Ordoyo finalizaba con un saldo ciertamente positivo. Tras las dificultades iniciales, había completado -como se ha visto- los pasos necesarios para hacer posible la inauguración del nuevo curso. Los resultados de la matrícula en el curso que concluía y las previsiones para el que se iniciaba eran ciertamente esperanzadores, toda vez que se habría registrado un muy leve descenso en el número de alumnos matriculados en las enseñanzas generales de Artes y Oficios y el reducido número de estudiantes inscritos en las enseñanzas impartidas por la Escuela Industrial parecía justificado por el hecho de tratarse de enseñanzas de nueva creación. Si algo podía lamentar era no haber conseguido, pese a las reiteradas reclamaciones, una mejora en las instalaciones con las que contaba la Escuela. Instalada provisionalmente en el edificio construido en su día para ser sede del Instituto de Segunda Enseñanza ${ }^{31}$, será constante la queja -no sólo en estos primeros años-, por su falta de adecuación a las necesidades de las enseñanzas profesionales ${ }^{32}$.

\footnotetext{
${ }^{30}$ Escuela Industrial y de Artes y Oficios de Logroño. Memoria del curso 1912 a 1913, Imprenta y Librería Moderna, Logroño, I9I3.

${ }^{31}$ Sobre el edificio del Instituto y las diferentes instituciones que fueron instalándose en el mismo, CERRILlO RUBIO, M.I., La formación de la ciudad contemporánea. Logroño entre 1850 y 1936. Desarrollo urbanístico y tipologías arquitectónicas, Logroño, Instituto de Estudios Riojanos, 1993, pp. 8I-82.

${ }^{32}$ En septiembre de I9I2 llamaban la atención sobre «el gravísimo inconveniente» que suponía no poder admitir a todos los alumnos que solicitaban su inscripción en las clases de Dibujo lineal y Dibujo artístico. Un problema que -entendían- de difícil solución mientras no se dispusiese de un edificio más amplio. Una situación que además vendría a agravarse con el inicio de un curso en el que comenzaba $\mathrm{n}$ a impartirse también los Peritajes.
} 
I.4. Estructura y funcionamiento de la Escuela.

La vida académica de la Escuela Industrial y de Artes y Oficios de Logroño aparece vinculada, desde el 2I de septiembre de I9I3 y hasta su supresión en I924, a la de un equipo directivo estable. En la Dirección, el profesor de Modelado y Vaciado, Rafael Gutiérrez de León y Alcalá del Olmo y al frente de la Secretaría y ejerciendo, además, el cargo de habilitado, los profesores de Dibujo Geométrico e Industrial y de Francés, respectivamente, Ruperto Gómez de Segura y Gerardo Olazábal Lacalle.

El equipo directivo de la Escuela habría contado durante este tiempo con el auxilio de los dos órganos colegiados previstos en el Reglamento orgánico para las Escuelas Industriales y las de Artes y Oficios, esto es, la Junta de profesores y la Junta económica del centro. Las noticias conservadas en relación a estas dos juntas son muy limitadas. A falta de los correspondientes libros de actas, debemos conformarnos con las referentes a su composición y funcionamiento, incluidas en el propio reglamento orgánico y en el reglamento particular de la Escuela logroñesa ${ }^{33}$. Por lo que se refiere a la Junta de profesores, se preveía que estuviese integrada por todos los profesores de término, debiendo incorporarse a la misma también los profesores de ascenso y de entrada que desempeñasen cátedras vacantes. Presididas por el director, el reglamento interior de la Escuela riojana contemplaba que la convocatoria pudiese ser instada por una tercera parte de sus miembros, debiendo indicarse, en ese caso, el objeto de la reunión. El propio reglamento precisaba el régimen de las convocatorias, el de las sesiones y el de la adopción de acuerdos en relación a determinadas cuestiones sometidas a la consideración de la Junta de profesores de la Escuela Industrial y de Artes y Oficios de Logroño. Por su parte, de acuerdo con las previsiones del reglamento orgánico, la Junta económica -a la que se atribuía el apoyo a la Dirección en todo lo relativo a la gestión y ejecución presupuestarias- estaría compuesta por el director, el secretario y el habilitado de la Escuela, que tendrían la consideración de vocales natos de la Junta, y por otros dos vocales elegidos por la Junta de profesores. En el caso de nuestra Escuela, el reglamento interior preveía que, en los supuestos en que una misma persona desempeñase dos de los cargos a los que estaba ligada la condición de miembro nato de la Junta económica -esto es, lo que ocurría efectivamente en la Escuela, en la que, como antes señalé, el cargo de habilitado estuvo ligado al secretario durante todo el período analizado- se incrementaría el número de vocales electivos hasta completar el total de cinco miembros. En lo tocante al régimen de funcionamiento de la Junta, cuyo pormenor correspondía determinar a los reglamentos interiores, se disponía que se reuniese al menos una vez al trimestre, estableciéndose además el régimen de mayorías para la adopción de acuerdos en el seno de la Junta.

Entre I9I2 y I924, la Escuela mantuvo -como puede observarse en el cuadro incluido al final- unos volúmenes de matrícula estables. Un total de 69 estudiantes concluyeron sus estudios de perito mecánico o electricista, en tanto otros 70 estaban aún pendientes de finalizar sus estudios al suprimirse la Escuela, por lo que fue preciso habilitar

\footnotetext{
${ }^{33}$ Real decreto de 16 de diciembre de I9ıо, por el que se aprueba el Reglamento orgánico para las Escuelas Industriales y las de Artes y Oficios, en Gaceta de Madrid del 28 de diciembre. El reglamento de régimen interior de la Escuela Industrial y de Artes y Oficios en Logroño en AUR, 6049. Incluyo una transcripción de este último texto en la última parte de este trabajo.
} 
un período transitorio en el que las enseñanzas de perito irían extinguiéndose de forma progresiva $^{34}$.

En el período estudiado pasaron por las aulas de la sección de Artes y Oficios cada año más de dos centenares de alumnos, que, como venía ocurriendo desde su establecimiento, continuaron manifestando una mayor inclinación hacia las asignaturas de Dibujo.

«Suele ser la inscripción más nutrida para la clase de Dibujo Lineal -indicarán en I924-; sigue en importancia la de Dibujo artístico; es regular la de Aritmética y Geometría, y, por último, es escasísima en Modelado y Vaciado. En las enseñanzas de Elementos de Física, Química y Mecánica, de Gramática y Caligrafía fue nula la matrícula»35.

Tampoco las enseñanzas impartidas en la Escuela experimentaron variaciones que merezcan ser reseñadas. El cuadro de enseñanzas se mantuvo estable, con tres excepciones de diferente alcance. De una parte, por la creación del Taller de Carpintería artística en I9I3, que comenzaría a funcionar en el curso I915-1 $6^{36}$. De otro lado, por la puesta en marcha de la reforma intentada por real decreto de 19 de agosto de $1915^{37}$, que perseguía una modificación del plan de estudios y la incorporación de enseñanzas de Aprendizaje y que se tradujo en el caso de nuestra Escuela en la momentánea inclusión de una nueva asignatura de Geometría y Trigonometría y en la elaboración por parte de la Escuela de un Plan de Aprendizajes que incluía aquellas especialidades que se consideraron adecuadas tanto por parte del claustro de profesores como por la de las autoridades locales y los representantes de las Sociedades Obreras a los que se consultós. Finalmente, por la reiterada manifestación por parte del director de su voluntad de implantar también enseñanzas destinadas a la mujer, que no se tradujo, sin embargo, en ningún proyecto concreto como el desarrollado en la Escuela entre 1903 y $1906^{39}$.

La situación financiera de la Escuela fue deteriorándose poco a poco, toda vez que la cantidad asignada en las sucesivas leyes de presupuestos para hacer frente a los gastos de

\footnotetext{
${ }^{34}$ A partir de 1924 ya no se admitieron nuevos ingresos, pero si se permitió a aquellos que habían iniciado sus enseñanzas que prosiguiesen sus estudios en la Escuela hasta obtener el título. Así, en el curso I924-25 hubo 45 alumnos oficiales y 25 de enseñanza no oficial, en el curso I925-26 fueron 23 las matrículas oficiales y 3 las libres, en el curso I926-27 descendió a los 20 y 2 alumnos, respectivamente. Finalmente, en el curso I92728, se matricularon aún 9 alumnos oficiales y i de enseñanzas no oficiales. Archivo General de la Administración (en adelante AGA), 32/1639I, exp. 6.

${ }^{35}$ AGA, 32/16540, Memoria de la Escuela Industrial de Logroño, años i923-24.

${ }^{36} \mathrm{La}$ autorización - por real orden de I2 de agosto de I9I3- para establecer un taller de carpintería artística se valoró como una importante mejora que permitiría al obrero «ilustrarse en sus oficios, llegando a poder ser un maestro en aquellos», Memoria de la Escuela Industrial de Logroño. Curso 1912-1913, cit.

${ }^{37}$ El real decreto de i9 de agosto de I9I5 por el que se aprueba el Reglamento Orgánico para las Escuelas de Artes e Industrias se publicó en la Gaceta de Madrid del 24 de agosto. Unos días después era necesaria una nueva publicación de algunos de sus artículos, tras detectarse algunas erratas y, solo una semana más tarde, una real orden de 7 de septiembre dejaba en suspenso la aplicación de la reforma, para el curso I9I5-I6, en lo tocante a las enseñanzas de peritaje, que continuarían de este modo impartiéndose en las mismas Escuelas y con la misma organización que venía haciéndose hasta entonces.

${ }^{38}$ Escuela Industrial y de Artes y Oficios de Logroño, Memoria. Curso 1915-1916, Imprenta y librería de El Riojano, Hijos de Aleson, Logroño, s.f.

${ }^{39}$ Sobre el particular, MARTÍNEZ NAVAS, I., «La enseñanza profesional para la mujer. Una experiencia municipal en el Logroño de comienzos del siglo XX», (en prensa).
} 
material resultaba a todas luces insuficiente tras la creación de la Sección Industrial ${ }^{40}$. Por lo que se refiere al estado de la Escuela Industrial y de Artes y Oficios de Logroño, en IgI4 llamarán la atención sobre el hecho de que sólo el alumbrado absorbe la mitad del presupuesto -que asciende a 4000 pesetas- con lo que «se hace poco menos que imposible la vida económica de este establecimiento», por lo que solicitarán un incremento de la dotación, argumentando que se habría autorizado ya en relación a otras escuelas ${ }^{41}$. De este modo, la adquisición de determinados equipos, o la factura de los gastos de pequeñas obras de instalación o de reforma de algunas dependencias, fueron posibles a duras penas merced a las aportaciones puntuales que se les giraban con esa finalidad. Las memorias anuales registran la cuantía de las subvenciones recibidas y las correspondientes justificaciones de gasto con cargo a las mismas. Junto a los datos estadísticos se incluyen además habitualmente en los discursos inaugurales las pertinentes muestras de agradecimiento a las instituciones de que se trate y también expresiones de lamento en los casos en que dejan de percibirse ${ }^{42}$.

Las buenas noticias escasearon también en lo tocante al sempiterno problema de la falta de adecuación del local en el que había sido instalada la Escuela. Si en I9I4 se felicitaban por el inicio de las obras de construcción de un nuevo edificio destinado a albergar las enseñanzas profesionales, diez años después dirán que el edificio proyectado no resulta adecuado a las necesidades de la Escuela.

«...no parece que hubo acierto en la elección, o no hubo proyecto con las características de una Escuela Industrial, pues el construido y próximo a terminar [...] para la Escuela de Artes y Oficios Artísticos, exclusivamente, es local amplio y capaz para contener talleres para labores manuales, el Museo de Reproducciones, y el reglamentario de la Escuela. Más si se destina a la instalación de varias instituciones docentes, no será posible contenerlas todas con la amplitud necesaria» ${ }^{43}$.

Es preciso, para concluir este apresurado repaso de las circunstancias por las que atravesó la Escuela Industrial y de Artes y Oficios de Logroño entre I9II y I924, hacer referencia al desgraciado incidente que finalizó con una sanción a la Escuela y a sus protagonistas. Los implicados fueron el director y el habilitado de la Escuela. Los hechos: una deuda no satisfecha a un proveedor en el año I922, la reclamación efectuada por éste,

$4^{40}$ En un estudio sobre la cuantía y distribución del gasto público en formación profesional se destaca el período I9I4-20 como el de mayor descenso del gasto medio por alumno, LOZANO LÓPEZ DE MEDRANO, C., «El gasto público en formación profesional industrial en España (I857-I935)», en Investigaciones de Historia Económica, núm. II, 2008, pp. 39-73.

${ }^{41}$ Escuela Industrial y de Artes y Oficios de Logroño. Memoria. Curso de 1913 a 1914, Imprenta Moderna, Logroño, I9I5.

${ }^{42}$ Así, por ejemplo, con ocasión de la suspensión por parte del Ayuntamiento de Logroño del abono de la subvención finalista que venía concediendo a la Escuela hasta el curso I9I4-I5 y que se destinaba a premios a los alumnos que destacaban en el cumplimiento de sus deberes, Escuela Industrial y de Artes y Oficios, Memoria. Curso 1915-16, Imprenta y Librería El Riojano, Logroño, s.f.

${ }^{43}$ Respecto a las deficiencias que imputan al proyecto, señalarán que «no tiene los talleres dispuestos con abundante luz, en condiciones para una buena instalación de maquinaria pesada y para el empleo de los elementos sucios (carbón, humo, grasas, tierras y materiales) que integran el trabajo. Es, por el contrario, una construcción lujosa de fachadas e interiormente repartida y decorada como para enseñanzas orales, gráficas y plásticas también; hasta para un Museo puede servir», AGA, 32/16540. 
la instrucción del correspondiente expediente gubernativo y la consignación de una cantidad suficiente para la satisfacción, en su caso, de la deuda ${ }^{44}$.

Pues bien, instruido el expediente se resolvió imponer una sanción de inhabilitación para el desempeño de cargos administrativos en Escuelas Industriales o de Artes y Oficios, por espacio de tres años, a los dos profesores investigados y se dispuso también una sanción para la Escuela, que debería «ser regida durante un año por persona extraña al Claustro, siendo revestida la persona que se encargue de la Dirección del expresado Centro Docente de las atribuciones propias de Comisario Regio».

El problema se planteó a la hora de ejecutar la sanción impuesta a la Escuela. La persona propuesta por el rector de la Universidad de Zaragoza fue Calixto Terés Garrido, catedrático del Instituto Nacional de Segunda Enseñanza de Logroño. Comunicado al Ministerio de Trabajo, Comercio e Industria, del que dependía desde el mes de marzo de I924 la Escuela Industrial, la respuesta fue que la sanción no alcanzaba al nuevo centro constituido en ese año, para el que parecía necesario además designar una persona especializada en las enseñanzas que debían impartirse en el mismo. El argumento desplegado por la Subsecretaría del Ministerio de Trabajo sería que al separarse, por real decreto de I5 de marzo de I924, la Sección Industrial de la Escuela mixta de Artes y Oficios de Logroño, constituyó en adelante un organismo nuevo, independiente en su régimen administrativo y en su organización de la anterior Escuela Industrial y de Artes y oficios. De este modo, no podía hacerse partícipe a la Escuela Industrial de la sanción impuesta a aquel otro centro educativo.

La tesis desplegada por la Subsecretaría del Ministerio de Trabajo, Comercio e Industria prosperó, de suerte que, el i8 de octubre de I924, era designado director de la Escuela Industrial el profesor de término de la misma e Ingeniero Industrial, Enrique Linés Nogueras, inaugurándose de ese modo un nuevo capítulo en los orígenes de la formación profesional en La Rioja ${ }^{45}$.

\section{El reglamento interior de I9I2}

El Reglamento orgánico de las Escuelas industriales y de las Escuelas de Artes y Oficios atribuía a la Junta de Profesores de cada centro la competencia para la formación de su reglamento interior particular. Posteriormente, el reglamento de cada Escuela debía someterse al necesario trámite de aprobación por el Ministerio de Instrucción Pública ${ }^{46}$.

En el caso de la Escuela Industrial y de Artes y Oficios de Logroño, al no haberse conservado los libros de actas de la Junta de Profesores, no es posible conocer los pormenores de la elaboración del reglamento, debiendo conformarnos con la noticia manuscrita anotada al pie del ejemplar del Reglamento interior de la Escuela según la cual fue «aprobado este Reglamento en Junta de Profesores celebrada en 30 de septiembre de I9I2» ${ }^{47}$. Por lo que se refiere a su aprobación por el Ministerio, la única noticia localizada es

${ }^{44}$ AGA, 32/I649I y AUR, 4965.

${ }^{45}$ AGA, 32/1649I.

${ }^{46}$ Real decreto de I6 de agosto de I9IO por el que se aprueba el Reglamento orgánico de las Escuelas..., cit.

${ }^{47}$ Reglamento interior de la Escuela Industrial y de Artes y Oficios de Logroño formado por la Junta de Profesores de la misma en cumplimiento de lo que se preceptúa en el párrafo primero del artículo i6 del 
la incluida en la Memoria reglamentaria del curso I9II-I9I2, fechada el I de octubre de este último año, en la que se alude a la reciente elaboración del reglamento por parte de la Junta de Profesores de la Escuela Industrial y de Artes y Oficios de Logroño, indicándose «que se elevará a V.E. para su aprobación». La Memoria correspondiente al siguiente curso no consigna ninguna otra noticia, ni siquiera la relativa a la modificación del texto, que si nos consta que fue realizada por la propia Junta de Profesores en el mes de febrero ${ }^{48}$.

El reglamento interior formado por la Escuela logroñesa es un texto extenso. Formado por 158 artículos, agrupados en capítulos, presenta un orden interno que no parece inspirado en el Reglamento orgánico, al que duplica en número de artículos.

Con una sistemática deficiente, el texto refleja en realidad la propia complejidad de la Escuela, su doble carácter. Se abordan, en primer término, bajo las rúbricas «Sección Industrial» (capítulos I-VI) y «Sección de Artes y Oficios» (capítulos VII-X) los aspectos particulares de cada uno de los centros reunidos en la Escuela, para, posteriormente, tratar aquellos que les son comunes a ambos, esto es, la Dirección, el Profesorado, la Secretaría, la Junta de Profesores, el personal administrativo y subalterno y la gestión económica de la Escuela (capítulos XI-XII).

La lectura detenida del reglamento permite conocer el alcance del ejercicio por parte de la Escuela del estrecho margen de autonomía reservado a estos centros educativos. Las disposiciones que habían canalizado la reforma en ı9ıо dejaban en manos de las respectivas Escuelas la decisión acerca de ciertos extremos tocantes al personal, a la gestión de la Escuela y a la ordenación académica. Así, en materia de ordenación académica, las Escuelas Industriales debían (i) proponer las especialidades en las que se impartirían las enseñanzas conducentes a la obtención de un certificado de aptitud como práctico industrial, (ii) fijar el tenor de los ejercicios de oposición a premio, o (iii) determinar la composición de los tribunales encargados de juzgar las pruebas de curso de los alumnos no oficiales, así como (iv) los grupos de asignaturas sobre los que serían examinados estos estudiantes. Por lo que se refiere al personal de la Escuela, el Reglamento orgánico atribuía a los diferentes centros la competencia para determinar las obligaciones de sus dependientes. Finalmente, en materia de gestión de la Escuela, cada reglamento interior debía establecer las reglas de funcionamiento de las Juntas Económicas. Junto a estos, el reglamento interior de la Escuela Industrial y de Artes y Oficios de Logroño atiende de manera minuciosa a otros muchos aspectos de la vida cotidiana en la misma. Incluye así algunas precisiones acerca de las atribuciones del director de la Escuela o las competencias de la Junta de Profesores, o sobre la solicitud de las pruebas de curso, entre otros extremos. Un documento que no es especialmente rico en su contenido, pero que constituye una buena aproximación a la vida académica en nuestra Escuela.

General de i6 de diciembre de I9Io, en AUR, caja 4965. Se trata de un ejemplar mecanografiado, sobre el que se introduce posteriormente la numeración de los diferentes capítulos y artículos desde el III y el I4, respectivamente.

${ }^{48}$ No es posible conocer el alcance de esa modificación acordada en sesión de 2I de febrero de I9I3, que debemos suponer muy limitado, toda vez que habría afectado a uno solo de los artículos del reglamento del que, además, tan solo nos consta su tenor literal tras la modificación, ibídem. 
III. Relación de personal docente, administrativo y de servicios, matrícula de la Escuela Industrial y cuadro de enseñanzas.

III.I. Relación de personal docente (I9II-I924)

RELACIÓN DE PROFESORES

\begin{tabular}{|c|c|c|}
\hline PROFESOR & CÁTEDRA QUE DESEMPEÑA & Categoría \\
\hline ASTARLOA BUSTO, Enrique** & $\begin{array}{l}\text { Química General } \\
\text { Electroquímica } \\
\text { Elementos de Mecánica, Física y Química }\end{array}$ & $\begin{array}{l}\text { Ayudante } \\
\text { meritorio }\end{array}$ \\
\hline BARRUSO FERNÁNDEZ, Antonio* & $\begin{array}{l}\text { Aritmética y Geometría prácticas } \\
\text { Elementos de construcción } \\
\text { Gramática castellana y Caligrafía }\end{array}$ & $\begin{array}{l}\text { Ayudante } \\
\text { meritorio }\end{array}$ \\
\hline CAPULINO JÁUREGUI, Joaquín & $\begin{array}{l}\text { Dibujo Artístico } \\
\text { Elementos de Historia del Arte }\end{array}$ & $\begin{array}{l}\text { Profesor de } \\
\text { término }\end{array}$ \\
\hline CLAVER SALAS, Mariano & $\begin{array}{l}\text { Nociones de Ciencias, Física y Química } \\
\text { Física General } \\
\text { Termotecnia }\end{array}$ & \\
\hline COLLADO, Pedro & Dibujo artístico & $\begin{array}{l}\text { Ayudante } \\
\text { meritorio }\end{array}$ \\
\hline CUARTIELLES CATALÁ, Rafael** & $\begin{array}{l}\text { Dibujo lineal } \\
\text { Dibujo industrial }\end{array}$ & $\begin{array}{l}\text { Profesor de } \\
\text { ascenso }\end{array}$ \\
\hline DÍAZ DE CERIO, Marco* & $\begin{array}{l}\text { Electrotecnia } \\
\text { Magnetismo y Electricidad }\end{array}$ & $\begin{array}{l}\text { Ayudante } \\
\text { meritorio }\end{array}$ \\
\hline FUENTES REDONDO, Ubaldo* & $\begin{array}{l}\text { Dibujo lineal } \\
\text { Dibujo artístico }\end{array}$ & $\begin{array}{l}\text { Profesor de } \\
\text { ascenso }\end{array}$ \\
\hline $\begin{array}{l}\text { GALBE SÁNCHEZ-PLAZUELOS, } \\
\text { Vicente* }\end{array}$ & $\begin{array}{l}\text { Nociones de Ciencias, Física y Química } \\
\text { Física General } \\
\text { Termotecnia }\end{array}$ & $\begin{array}{l}\text { Profesor de } \\
\text { término }\end{array}$ \\
\hline GARBAYO RIBOT, Eduardo* & $\begin{array}{l}\text { Mecanismos y máquinas-herramientas } \\
\text { Herramientas y motores }\end{array}$ & $\begin{array}{l}\text { Ayudante } \\
\text { meritorio }\end{array}$ \\
\hline $\begin{array}{l}\text { GÓMEZ DE SEGURA AMÉRICA, } \\
\text { Ruperto* }\end{array}$ & $\begin{array}{l}\text { Dibujo geométrico } \\
\text { Dibujo industrial }\end{array}$ & $\begin{array}{l}\text { Profesor de } \\
\text { término }\end{array}$ \\
\hline GUTIÉRREZ DE LEÓN LÓPEZ, Rafael** & Modelado y Vaciado & $\begin{array}{l}\text { Profesor de } \\
\text { término }\end{array}$ \\
\hline HOYOS JULIÁ, Miguel** & $\begin{array}{l}\text { Aritmética y Geometría prácticas } \\
\text { Geometría plana y del espacio } \\
\text { Trigonometría y Topografía }\end{array}$ & $\begin{array}{l}\text { Ayudante } \\
\text { meritorio }\end{array}$ \\
\hline LAFUENTE ASTRAÍN, Dámaso & Taller Mecánico & Ayudante de taller \\
\hline LINÉS NOGUERAS, Enrique* & $\begin{array}{l}\text { Aritmética y Álgebra } \\
\text { Ampliación de matemáticas } \\
\text { Geometría descriptiva }\end{array}$ & $\begin{array}{l}\text { Profesor de } \\
\text { término }\end{array}$ \\
\hline LÓPEZ MERINO, Bernabé* & Nociones de Ciencias Físicas, Químicas y & Ayudante \\
\hline
\end{tabular}




\begin{tabular}{|c|c|c|}
\hline & Naturales & meritorio \\
\hline & Física General & \\
\hline & Termotecnia & \\
\hline MAGUREGUI CALERO, Bonifacio & Economía y Legislación Industrial & Ayudante \\
\hline & Geografía Industrial & meritorio \\
\hline MARROYO GAGO, Benigno* & Aritmética y Álgebra & Ayudante \\
\hline & Ampliación de matemáticas & meritorio \\
\hline & Geometría descriptiva & \\
\hline OLAZÁBAL LACALLE, Gerardo* & Idiomas & $\begin{array}{l}\text { Profesor de } \\
\text { término }\end{array}$ \\
\hline PÉREZ ORDOYO, Manuel* & Mecánica general & Profesor de \\
\hline & Mecánica aplicada & \\
\hline ROY NIS, Alfredo & Taller mecánico & Maestro de taller \\
\hline RUIZ DE CENZANO, Quirino* & & Profesor de entrada \\
\hline SÁEZ-BENITO, Marcelino* & Idioma (francés) & $\begin{array}{l}\text { Ayudante } \\
\text { meritorio }\end{array}$ \\
\hline VIDAL HERNÁNDEZ, Luis* & & $\begin{array}{l}\text { Ayudante } \\
\text { meritorio }\end{array}$ \\
\hline VINÓS SANTOS, Ricardo* & Aritmética y Geometría prácticas & Profesor de \\
\hline & Geometría plana y del espacio & \\
\hline & Trigonometría y Topografía & \\
\hline
\end{tabular}

FUENTE: AHPLR, EAD, legs. I35 a I37

III.2. Relación del personal administrativo y de servicios (I9II-I924)

RELACIÓN DEL PERSONAL ADMINISTRATIVO Y DE SERVICIOS

\begin{tabular}{ll}
\hline NOMBRE & PUESTO QUE DESEMPEÑA \\
\hline AJAMIL MARTÍNEZ, Francisco & Mozo de aseo \\
\hline ALONSO ILORO, Bernabé & Portero $4^{\circ}$ \\
\hline BASTIDA NIETO, Francisco & Mozo de aseo \\
\hline CONTRERAS ARNÁIZ, Francisco & Oficial $4^{\circ}$ \\
\hline CURTO FERREZ, Federico & Conserje \\
\hline ELIAS GONZÁLEZ, Juan & Oficial de Secretaría \\
\hline JIMÉNEZ SÁNCHEZ, Eloy & Mozo de aseo \\
\hline MARTÍNEZ SÁENZ, Fidel & Escribiente \\
\hline PIÑOL IBÁÑEZ, David & Vaciador \\
\hline RUIZ DE CENZANO, Quirino & Mozo de aseo \\
\hline SALAZAR, Juan & Bedel \\
\hline VALIENTE, Francisco & Oficial de Secretaría \\
\hline VIDAL HERNÁNDEZ, Luis &
\end{tabular}


FUENTE: AHPLR, EAD, legs. I36-I37

III.3. Evolución de la matrícula y resultados en la Sección Industrial (I9I2-1924)

\begin{tabular}{|c|c|c|c|c|}
\hline & Matrícula* & Inscripciones & Aptos & Ingreso \\
\hline Curso I9I2-I3 & $23 / 6$ & 92 & 56 & 9 \\
\hline Curso I9I3-I4 & $16 / 0$ & $8 \mathrm{I}$ & 45 & 22 \\
\hline Curso I9I4-I5 & $2 \mathrm{I} / 2$ & IIO & 80 & 24 \\
\hline Curso I9I5-I6 & $22 / 5$ & I27 & 94 & 26 \\
\hline Curso I9I6-I7 & $24 / 3$ & I28 & 98 & 29 \\
\hline Curso I9I7-I8 & $36 / 13$ & $2 \mathrm{I} 3$ & I67 & 33 \\
\hline Curso I9I8-I9 & $3 \mathrm{I} / 4$ & I9I & I44 & 35 \\
\hline Curso I9I9-20 & $33 / \mathrm{I} 2$ & 246 & 156 & 33 \\
\hline Curso I920-2I & $35 / 18$ & 256 & I80 & 35 \\
\hline Curso I92I-22 & $33 / 19$ & 300 & 230 & 50 \\
\hline Curso I922-23 & $34 / 32$ & 333 & I97 & I3 \\
\hline Curso I923-24 & $50 / 2 \mathrm{I}$ & 326 & 228 & \\
\hline
\end{tabular}

FUENTE: Memorias reglamentarias de los cursos I9II-I2, I9I2-I3, I9I3-I4, I9I5-I6 y I923-24; AGA, 32/I6540, exp. 5 .

*La primera cifra corresponde a alumnos oficiales y la segunda a la matrícula no oficial.

III.4. Cuadro de enseñanzas (I923-I924)

ESCUELA INDUSTRIAL Y DE ARTES Y OFICIOS DE LOGROÑO

\begin{tabular}{lll}
\hline \multicolumn{2}{l}{ SECCIÓN INDUSTRIAL } \\
\hline Curso preparatorio & & \\
\hline Aritmética y Geometría prácticas & & \\
\hline $\begin{array}{l}\text { Nociones de Ciencias Físicas, } \\
\text { Químicas y Naturales }\end{array}$ & Geografía industrial & $\begin{array}{l}\text { Conferencias tecnológicas en los } \\
\text { talleres sobre el hierro y } \\
\text { herramientas de cerrajería y } \\
\text { prácticas de lima }\end{array}$ \\
\hline Primer grupo & Francés (Ier curso) & \\
\hline Aritmética y Álgebra & & Conferencias ajuste y forja \\
\hline Geometría plan y del espacio & & Prácticas de ajuste y forja \\
\hline Segundo grupo & Francés (2 ${ }^{\circ}$ curso) & \\
\hline Trigonometría y topografía & & \\
\hline Ampliación de matemáticas & & \\
\hline
\end{tabular}


Mecánica general Dibujo geométrico ( $2^{\circ}$ curso $)$

\begin{tabular}{|c|c|c|}
\hline \multicolumn{3}{|l|}{ Tercer grupo } \\
\hline Geometría descriptiva & Termotecnia & Dibujo industrial (Ier curso) \\
\hline \multirow[t]{2}{*}{ Mecánica aplicada } & Química general & $\begin{array}{l}\text { Conferencias en los talleres de } \\
\text { fundición }\end{array}$ \\
\hline & & $\begin{array}{l}\text { Prácticas del tercer grupo de } \\
\text { electricistas }\end{array}$ \\
\hline \multicolumn{3}{|l|}{ Cuarto grupo (Mecánicos) } \\
\hline $\begin{array}{l}\text { Mecanismos y máquinas- } \\
\text { herramientas }\end{array}$ & Economía y Legislación industrial & $\begin{array}{l}\text { Prácticas de taller, modelaje y } \\
\text { construcción de mecanismos y } \\
\text { piezas de máquinas, conducción y } \\
\text { ensayo de motores }\end{array}$ \\
\hline Motores & Dibujo industrial $\left(2^{\circ}\right.$ curso $)$ & \\
\hline \multicolumn{3}{|l|}{ Cuarto grupo (Electricistas) } \\
\hline Magnetismo y electricidad & Electrotecnia & \\
\hline Electroquímica & $\begin{array}{l}\text { Prácticas del cuarto grupo de } \\
\text { electricistas }\end{array}$ & \\
\hline \multicolumn{3}{|c|}{ SECCIÓN DE ARTES Y OFICIOS } \\
\hline Gramática castellana y caligrafía & $\begin{array}{l}\text { Elementos de mecánica, física y } \\
\text { química }\end{array}$ & Modelado y vaciado \\
\hline Aritmética y geometría prácticas & Dibujo lineal & Taller de carpintería artística \\
\hline Elementos de construcción & Dibujo artístico & \\
\hline
\end{tabular}

FUENTE: AGA, 32/16540; Memoria de la Escuela Industrial de Logroño, años 1923-24; AUR, 6046.

\section{Reglamento de régimen interior de la Escuela Industrial y de Artes y Oficios de Logroño ${ }^{49}$}

«Reglamento interior de la Escuela Industrial y de Artes y Oficios de Logroño, formado por la Junta de Profesores de la misma, en cumplimiento de lo que se preceptúa en el párrafo primero del artículo i6 del general de i6 de Diciembre de igio.

\section{SECCIÓN INDUSTRIAL}

\section{CAPÍTULO I}

De las enseñanzas

Art. I․- Las enseñanzas de esta Sección según el RD de I9 de Octubre de I9II, han de ser las de los peritajes industriales de Mecánicos y de Electricistas.

Art. $2^{\circ}$.- Para cumplimentar el art. $5^{\circ}$ del Reglamento orgánico, esta Escuela también expedirá certificados de aptitud en las especialidades que se expresan a continuación y mediante los cursos de asignaturas que los integran.

${ }^{49}$ El texto transcrito corresponde al ejemplar conservado en AUR, caja 4965. En la transcripción del texto he procurado respetar el aspecto formal del texto, lo que permite explicar (i) la utilización o no de abreviaturas y signos de puntuación en los diferentes capítulos, (ii) el orden inadecuado en el que se insertan algunos artículos o la falta de éstos, (iii) así como la falta de numeración de algunos capítulos y -en la parte final del texto-, la reunión bajo un mismo capítulo de diferentes artículos que, de acuerdo con la estructura del documento, deberían haber configurado capítulos independientes. 
Para la especialidad de

Ajustador de banco

Primer curso.

Aritmética y Geometría prácticas. Dibujo geométrico (primer curso). Conferencias y prácticas de ajuste.

Segundo curso.

Nociones de Ciencias físicas, químicas y naturales. Dibujo geométrico ( $2^{\circ}$ curso). Prácticas de ajuste y forja.

Tornero ajustador

Las mismas asignaturas, pero con Prácticas de torno.

Montador mecánico

Los dos cursos anteriores y además:

Tercer curso

Mecánica general. Física general. Mecanismos y motores. Prácticas de conducción y ensayo de motores.

Montador electricista

Los dos cursos primeros y además:

Tercer curso

Química general. Magnetismo y Electricidad. Prácticas de manejo, reparación, etc. de dinamos.

Art. $3^{\circ}$.- Los profesores de las respectivas asignaturas determinarán lo que de ellas sea necesario para que cada una de las especialidades enumeradas en el artículo anterior para someterlo a la aprobación de la Junta de Profesores.

\section{CAPÍTULO II}

De los talleres y laboratorios

Art. $4^{\circ}$.- Habrá en la Escuela talleres para prácticas de los alumnos de la enseñanza general y de las enseñanzas profesionales.

Art. $5^{\circ}$.- Estos talleres comprenderán el trabajo de los metales y de la madera, la construcción de órganos y montaje de máquinas y aparatos de conducción, reparación de motores, principales aplicaciones de la industria eléctrica, fundición y los demás que las necesidades de la Escuela puedan exigir, previo acuerdo de la Junta de profesores y aprobación de la Superioridad.

Art. $6^{\circ}$.- Las prácticas de taller para los alumnos profesionales son obligatorias con arreglo a las disposiciones del Reglamento orgánico vigente.

Art. $7^{\circ}$.- Los alumnos de la enseñanza general podrán asistir a los talleres cuando lo determine el Profesor de la respectiva asignatura.

Art. $8^{\circ}$. El Director de la Escuela, previo informe del jefe del taller respectivo, podrá autorizar que tomen parte en los ejercicios prácticos a los oficiales o maestros de taller que lo pretendan sin ser alumnos de la Escuela, así como dispensar de la asistencia a estas prácticas a los alumnos artesanos que, por trabajar en un taller particular afin, no puedan asistir al de la Escuela.

Art. $9^{\circ}$.- Cada jefe de taller redactará el programa y organizará los trabajos en la forma que estime más conveniente, dando cuenta al Director para someterlo a la Junta de profesores.

Art. Io .- El jefe del taller será también jefe del maestro de taller afecto al mismo y demás personal subalterno.

Art. II $^{\circ}$.- Los jefes de taller recibirán por inventario todo el material del mismo. Los maestros de taller recibirán también por inventario, del jefe del taller las primeras materias y herramientas de la dependencia de su cargo.

Art. I2․- Además de las prácticas generales, se realizarán en los talleres las especiales que los Profesores de la Escuela estimen necesarias para completar las enseñanzas teóricas de sus respectivas asignaturas, para estos efectos se pondrán de acuerdo con el jefe del taller respectivo.

Art. I4. - Los trabajos en los laboratorios estarán sometidos a las disposiciones siguientes:

$I^{\circ}$.- Las horas de prácticas en los laboratorios se determinarán en cada curso por el Director de la Escuela oyendo a los respectivos Profesores.

$2^{\text {a }}$ - El profesor podrá negar la entrada a las practicas del día al alumno que no asista puntualmente. 
$3^{\mathrm{a}}$.- los alumnos que falten tres días consecutivos a las practicas o seis días con interrupción y sin justificación favorable, podrán ser borrados de la lista.

$4^{a}$.- los alumnos tendrán la obligación de tomar las notas y hacer los cálculos y observaciones que el Profesor crea convenientes.

5a.- El Profesor podrá entregar a los alumnos el material y libros necesarios para el trabajo que se les encomiende, exigiéndoles (¿), si lo cree conveniente, recibos firmados por ellos, quienes serán responsables de los deterioros ocasionados por negligencia o impericia manifiesta, y obligándose a devolverlos inmediatamente después de terminadas las operaciones en que aquel material se haya invertido.

6a.- las personas que, con autorización del Profesor, concurran a los laboratorios para asistir a las conferencia o para efectuar trabajos especiales, quedan sometidas al régimen que verbalmente se les indique al concederles el oportuno permiso.

$7^{\text {a }}$ - Por interés de higiene general, se prohíbe escupir en el suelo y fumar en los laboratorios, lo primero en absoluto y lo segundo en las horas de trabajo.

Art. I3. Los alumnos que asistan a los talleres mecánicos de la Escuela, llevarán las siguientes herramientas de su propiedad:Una lima carleta guardacantos bastos de I2 pulgadas. Una id.id. de io pulgadas. Una carletilla basta de 8 pulgadas. Una cruceta. Una media caña basta de diez pulgadas. Una id.id. de 8 id. Una id.id. de 6 id. Un limatón basto de io pulgadas. Un id.id. de 8 id. Un id. cola de ratón de 5 pulgadas. Un limatón cuadrado de Io pulgadas. Un id.id.id. de 6 pulgadas. Un triángulo de 8 pulgadas. Una lima cuchilla de 6 pulgadas. Una carleta muza de io pulgadas. Una id.id. de 6 id. Una media caña muza de ıo pulgadas. Una id.id. de 8 id. Una id.id. de 6 id. Un limatón redondo muzo. Un cortafríos de 25 por io milímetros. Un buril. Un punzón redondo. Un id. cuadrado. Unas tenacillas de electricista. Una escuadra de acón. Un calibrador. Un granete. Un compás de puntas. Un id. de grueso. Una punta de trazar. Un martillo pequeño. Una broca de culata cuadrada de 6 milímetros. Una id. de 7 id. Cinco brocas para taladrar en la máquina de bolas y en el torno, Salomónicas de los números I, 2, 34 y 5 milímetros.

Estas herramientas quedarán bajo la custodia de la Escuela durante el curso, pudiendo retirarlas el alumno a su terminación o cuando dejare de pertenecer a la Escuela.

Art. I5.- Si el número de alumnos que estén en condiciones de asistir a los laboratorios y talleres de la Escuela, excediere de las plazas disponibles en cada uno de ellos, se dará preferencia a los que hubieren obtenido mejores calificaciones en los cursos anteriores.

\section{CAPÍTULO $[I I I]$}

De los alumnos

Art. I6. Los alumnos de esta Sección, bien sean oficiales o no oficiales, se dividirán en dos clases:

\section{De Enseñanzas Generales}

De Enseñanzas Profesionales

Pertenecerán a las enseñanzas generales aquellos que cursen asignaturas sin validez académica, y por tanto sin sujeción a prelación alguna o los que se someten a un orden especial con el propósito de adquirir un Certificado de aptitud de las especialidades indicadas en el articulo $2^{\circ}$.

Pertenecerán a las enseñanzas profesionales los que cursen sistemáticamente el plan de estudios correspondiente para obtener en su día el Título de Perito.

Artículo I7. - Los que aspiren a ingresar en esta Sección en calidad de alumnos oficiales y con validez académica, durante la primera quincena del mes de Septiembre, solicitarán el examen de Ingreso en instancia dirigida al Director de la Escuela. A esta instancia, que deberá estar escrita por el interesado, se acompañará Certificación del Registro Civil, que acredite ser mayor de I2 años.

Los alumnos que deseen justificar en una segunda prueba que poseen los conocimientos que constituyen el curso Preparatorio de los Peritajes, lo harán constar así en la instancia a que se refiere el párrafo anterior.

Previo abono de los derechos correspondientes, si el aspirante no justifica su calidad de artesano o hijo de artesano, la Secretaría admitirá provisionalmente estos documentos, entregando al interesado un resguardo que le sirva para presentarse a dicho examen el día que se le designe, si no estuviese dispensado de este ejercicio.

Artículo I8.- La matrícula ordinaria estará abierta en la Secretaría de la Escuela del I5 al 30 de Septiembre y la extraordinaria, con abono de derechos dobles, durante el mes de Octubre. Los aspirantes solicitarán la matrícula por medio de impresos que se les facilitará en la portería, indicando las asignaturas que hayan de cursar.

Artículo i9.- las condiciones de matrícula y la agrupación y orden de los estudios para los alumnos de la enseñanza profesional y para los especiales de las generales, serán las que determinan los artículos correspondientes de este Reglamente Interior y del Reglamento Orgánico vigente. 
Artículo 20.- En armonía con el artículo 43 del citado Reglamento Orgánico, los alumnos oficiales que no justifiquen su condición de artesanos o hijos de artesano, al hacer la inscripción de sus matrículas, abonarán en papel de Pagos al Estado la cantidad de ocho pesetas por asignatura en concepto de derechos de matrícula y veinte pesetas en metálico por derechos de todo el grupo de Prácticas de taller y de asignaturas. En el mes de Abril abonarán cuatro pesetas por asignatura por los derechos académicos, en la misma forma que está dispuesto actualmente para los Institutos generales y técnicos.

Artículo 2I.- Para hacer efectiva la inscripción gratuita en las Escuelas Industriales que el artículo 43 de Reglamento Orgánico concede a los artesanos e hijos de artesano, será preciso que el alumno pruebe ser artesano si pasa de los I4 años, o hijo de artesano si no llega a esta edad. Esta condición de artesano que, según los casos ha de reunir el padre o el hijo, se acreditará por Certificación expedida por el maestro o jefe del taller donde trabaje el interesado, pudiendo exigir además la Secretaría de la Escuela si lo estima necesario, declaración firmada de dos operarios de aquel taller en la que atestigüen conocerle como tal artesano y compañero en el mismo.

También quedarán exentos del pago de derechos de Prácticas los artesanos que por pertenecer a oficio similar a las Practicas del grupo correspondiente puedan ser dispensados de cursarlas, pero serán sometidos a las pruebas necesarias para justificar esta concesión.

Artículo 22.- En las clases orales en que el número de alumnos matriculados resulte excesivo, podrá el Director, oyendo al Profesor correspondiente, dividirla en dos Secciones desempeñadas una por el mismo Profesor y otra por el Auxiliar adscrito, teniendo en cuenta que deben ser las mismas horas de clase para ambas Secciones, con el objeto de no hacerlas incompatibles con las restantes a que haya de asistir el alumno.

Artículo 23.- Desde el momento de su ingreso en la Escuela quedarán los alumnos sujetos a la autoridad del Director, Profesores y Auxiliares en todo cuanto se refiera al orden y disciplina académicas, entendiéndose comprendidos en esta disposición, tanto los alumnos oficiales que asistan a las clases como los oyentes no inscriptos en la matricula.

Artículo 24.- Los alumnos no oficiales que deseen asistir a las clases prácticas, solicitarán autorización del Director y concedida esta, quedarán sometidos a todas las disposiciones dictadas para los oficiales.

Artículo 25.- las clases serán públicas. Sin embargo, para asistir a ellas en calidad de oyente, será necesaria la autorización de los Profesores respectivos. En las Prácticas se admitirán también alumnos no oficiales, previo informe del Profesor respectivo y abono de los derechos correspondientes.

Artículo 26.- Las inscripciones de alumnos no oficiales se harán en las segundas quincenas de los meses de mayo y Octubre, mediante instancia de los interesados en impresos que se les facilitarán en la Escuela.

Al entregar dichas instancias abonarán en la misma forma y por los mismos conceptos que actualmente está establecido para los Institutos generales y técnicos, la cantidad de catorce pesetas cincuenta céntimos por asignatura, entendiéndose que los derechos de cada grupo serán los equivalentes al número de asignaturas que lo integran.

Artículo 27.- El alumno que no se presente a examen o no sea aprobado en la convocatoria en que haya solicitado su inscripción, podrá situarlo en la inmediata, pero pasada esta, caducarán todos los derechos que conceden estas matrículas y en su virtud, los alumnos que no estuviesen examinados, así como los que no hubiesen sido declarados aptos, necesitarán nuevas matrículas para las convocatorias sucesivas.

Artículo 28.- El alumno que cometiere faltas contra la disciplina y régimen escolar, sufrirá, en cada caso, los castigos que se establecen en el artículo 67 del Reglamento general y demás disposiciones vigentes.

Artículo 29.- Las clases prácticas que se dan en los talleres tienen igual carácter que las orales dadas en la Escuela y por lo tanto, los alumnos observarán en ellas todas las disposiciones dictadas para estas respecto a asistencia, puntualidad, orden, etc.

Artículo 30.- Cuando existan alumnos pensionados, la Dirección de la Escuela comunicará a las Corporaciones o particulares que costeen la pensión, las noticias que deseen, tener acerca de la aplicación y aprovechamiento de dichos alumnos y estos tendrán la obligación de cursar las asignaturas en los grupos y tiempo que se determinan en este Reglamento.

Artículo 3I.- Toda reclamación o instancia dirigida a la Superioridad por los alumnos, deberá tramitarse por conducto del Director de la Escuela y a este corresponde darla curso o no, bajo su responsabilidad.

Estas reclamaciones serán solo cursadas cuando las haga cada alumno por sí y en representación propia y no en colectividad o a nombre de otros, circunstancia esta última que se considerará como falta de disciplina.

\section{CAPÍTULO $[I V]$}

De las pensiones y de los pensionados

Artículo 32.- Las pensiones que disfruten los alumnos de esta Sección, serán reglamentarias y extraordinarias. 
Artículo 33.- Corresponden a las primeras las que se determinan en el artículo 47 del Reglamento Orgánico vigentes.

Son extraordinarias las concedidas conforme al artículo 48 por las Diputaciones, Ayuntamientos o particulares.

Artículo 34.- Las pensiones reglamentarias se proveerán por la Junta de Profesores, previo concurso.

Las pensiones que hayan de proveerse se anunciarán el día i ${ }^{\circ}$ de Septiembre en el tablón de edictos de la Escuela, en la Gaceta y en el Boletín de la provincia, señalándose el término de un mes para presentar solicitudes dirigidas al Director de la Escuela, acompañadas de los documentos que acrediten el derecho a concursar de los aspirantes.

Artículo 35.- Para aspirar a esta recompensa se necesita acreditar:

Carecer de recursos con que atender a los gastos que ocasione la enseñanza.

Ser alumno de la Escuela, llevando por lo menos dos años de enseñanza técnica o uno en la enseñanza especial, aspirando a un certificado de aptitud.

Los estudios y prácticas hechos en la Escuela.

Los premios y accésit que hubiese obtenido.

Artículo 36.- La carencia de recursos se justificará con certificado del párrafo o alcalde respectivo; los estudios y prácticas hechos en la Escuela, con volante de la Secretaría de la misma y los premios y accésit con el diploma correspondiente.

Artículo 37.- Terminado el plazo para la admisión de solicitudes la Secretaría de la Escuela, practicará las comprobaciones referentes a los documentos de pobreza, estudios y prácticas y premios expresados en la solicitud, y pedirá informes a los Profesores respectivos acerca de la conducta observada, aptitud para el estudio, aprovechamiento y cuanto fuere de exponer del aspirante para ilustrar debidamente el expediente, excluyendo desde luego, del concurso, de acuerdo con el Director de la Escuela, a los que no tuviesen las condiciones de la convocatoria.

Artículo 38.- En la primera decena de Noviembre pasará la Secretaría el expediente ya completo á la Junta Económica.

Artículo 39.- El día I5 de Noviembre se constituirá la Junta para estudiar los expedientes de los aspirantes, celebrará las sesiones que estime conveniente, y el día I5 de Diciembre someterá a la Dirección de la Escuela la propuesta acordada por mayoría absoluta de votos.

Artículo 40.- La Junta de Profesores se reunirá inmediatamente y resolverá en definitiva en vista de la propuesta, también por mayoría absoluta de votos, y el Director de la Escuela circulará las órdenes oportunas a fin de que los agraciados comiencen a percibir sus haberes desde $\mathrm{I}^{\mathrm{o}}$ de Enero.

Artículo 4I.- Estas pensiones terminarán cuando el interesado haya concluido los estudios a que pertenecía al aspirar a la pensión, siempre que no incurriese en las excepciones que por este Reglamento se establecen.

Artículo 42.- Los alumnos pensionados tienen la obligación ineludible de cursar en cada año escolar el grupo de asignaturas y prácticas designado, si son de la sección técnica, y los que aspiren al certificado de aptitud, las que para cada curso les señale el Director de la Escuela. Al hacerse esta designación por la Dirección se tendrá en cuenta el número de clases a que se obliga a asistir a los técnicos, atemperándose para los de la enseñanza especial al número de asignaturas que constituyen el grupo, con el fin de establecer la justa igualdad de trabajo y de tiempo para todos.

Artículo 43.- La pérdida de curso en cualquiera de las asignaturas supone la pérdida de la pensión reglamentaria.

Artículo 44.- El pensionado que faltare quince días a clase sin causa debidamente justificada ante el Director de la Escuela, no figurará en la nómina correspondiente al mes en que cumplió aquel número de faltas; treinta días sin asistir a clase sin causa justa, también a juicio del Director, darán lugar a la pérdida de la pensión reglamentaria y si la pensión fuese extraordinaria, a la suspensión de pago y propuesta de cese a la Superioridad. Estas penas comprenden también toda pensión otorgada por Corporaciones o particulares.

Artículo 45.- Las subvenciones a que hace referencia el artículo 66 del Reglamento orgánico, se concederán previa oposición ante un Tribunal formado de un modo análogo al que se establece para las Reválidas. Este Tribunal determinará en cada caso los ejercicios que deban realizar los opositores, al disfrute de la subvención.

\section{CAPÍTULO V}

De las pruebas de curso

Artículo 46.- En la segunda quincena de Abril los alumnos que aspiren a figurar en las relaciones de aptitud a que se refiere el artículo 49 del Reglamento orgánico, lo solicitarán en un impreso que se les facilitará en la Secretaría de la Escuela, la cual pasará a cada Profesor la relación de los que lo hayan solicitado. 
Artículo 47.- Cada Profesor en vista de la relación de solicitudes que se le haya pasado por la Secretaría, formará la lista de los alumnos que en su asignatura hayan merecido la declaración de aptitud.

Artículo 48.- Los alumnos oficiales que no hubiesen merecido ser incluidos en las relaciones de aptitud formadas en el mes de Mayo, podrán solicitar su inclusión en el mes de Septiembre que se les concederá si del examen de la asignatura que habrán de realizar ante un Tribunal formado como determina el artículo 57 de este Reglamento resultasen declarados aptos.

Artículo 49.- Podrán concederse premios de Mérito que serán ordinarios y extraordinarios. Los primeros se adjudicarán por asignaturas mediante oposición entre los alumnos que figuren en las correspondientes relaciones de aptitud.

Los segundos, lo serán por cada uno de los grupos de asignaturas homogéneas establecidos en los diferentes Peritajes. Se adjudicarán igualmente por oposición.

Los ejercicios de oposición para unos y otros consistirán en un ejercicio oral y otro práctico, que determinarán en cada caso los correspondientes Tribunales.

Los Tribunales para estos premios se formarán por el Director de la Escuela. Los que han de juzgar los ejercicios a premios ordinarios, se constituirán con tres Profesores del grupo correspondiente, siendo vocal nato el Profesor de la asignatura objeto de la oposición.

Los de los premios extraordinarios se constituirán con todos los Profesores del grupo.

Artículo 50.- Los premios podrán consistir en un diploma y en una cantidad en metálico o en instrumentos, libros o herramientas del oficio o profesión a que corresponda la enseñanza, y estarán en número proporcionado con los recursos que cuente la Escuela para este objeto y con los alumnos que hayan sido declarados aptos.

Artículo 51.- A este fin, en la última decena de Mayo podrán concederse un premio ordinario por cada veinticinco alumnos o fracción de veinticinco declarados aptos en cada asignatura, y en la primera quincena de Septiembre la Junta de Profesores determinará, vistos los recursos con que cuenta la Escuela y el número de premios ordinarios ya concedidos tanto en esta Sección como en la de Artes y Oficios, si procede o no la adjudicación de premios extraordinarios, fijando en el primer caso su número, de tal modo, que el total de premios de todas las clases que resulten adjudicados en ambas secciones de la Escuela, se halla en armonía con lo preceptuado en el artículo anterior.

Artículo 52.- Las oposiciones a premios ordinarios tendrán lugar en los días inmediatos a la terminación del curso y las de los extraordinarios, si hubiese lugar a ello, se verificarán en la segunda quincena de Septiembre.

Artículo 53.- Los exámenes de Ingreso se verificarán ante un Tribunal formado por tres Profesores de la Escuela nombrados por el Director.

Artículo 54.- Los exámenes de asignaturas, si hubiese lugar a ello o los de grupos de materias homogéneas a que han de someterse los alumnos no oficiales, se verificarán por medio del programa oficial de la asignatura en el primer caso y por un cuestionario formado para este objeto por los Profesores del grupo respectivo en el segundo.

Estas pruebas comprenderán dos ejercicios: Uno práctico, en armonía con la asignatura o grupo de enseñanzas objeto del examen y otro oral en el que contestarán a dos temas del programa o cuestionario sacados a la suerte. El Tribunal podrá hacer además las preguntas que estime oportunas para cerciorarse de la aptitud del examinado.

Artículo 55.- Para los exámenes de prácticas de taller los aspirantes deberán presentar una relación de los trabajos ejecutados. El Tribunal hará sobre la misma cuantas preguntas estime oportunas y dispondrá la repetición de un trabajo de los hechos en las prácticas oficiales. A cada fin, los examinados llevarán las herramientas de mano que necesiten.

Artículo 56.- Las notas de calificación de los exámenes de los alumnos no oficiales serán las de Apto o No apto.

Artículo 57.- Los Tribunales de examen para estos alumnos se constituirán con tres Profesores del grupo correspondiente, nombrados por el Director de la Escuela de acuerdo con la Junta de Profesores.

Artículo 58.- Los grupos de asignaturas con arreglo a los cuales han de verificarse los exámenes de los alumnos no oficiales y el orden de prelación, será el siguiente:

Ingreso

Preparatorio

Peritos mecánicos:

Primer grupo.- Aritmética y Álgebra, Geometría plana y del espacio y Trigonometría y Topografía.

Segundo grupo.- Física general y Química general.

Tercer grupo.- Mecánica general y Mecánica aplicada. 
Cuarto grupo.- Ampliación de Matemáticas y Geometría descriptiva.

Quinto grupo-- Mecanismos, Máquinas-herramientas y Construcción de máquinas.

Sexto grupo.- Termotecnia y Motores.

Séptimo grupo.- Francés $\left(\mathrm{I}^{\circ}\right.$ y $2^{\circ}$ curso)

Octavo grupo.- Geografía industrial y Economía y Legislación industrial.

Noveno grupo.- Dibujo geométrico $\left(\mathrm{I}^{\mathrm{o}}\right.$ y $2^{\circ}$ curso).

Décimo grupo.- Dibujo industrial ( $\mathrm{I}^{\mathrm{o}}$ y $\left.2^{\circ} \mathrm{curso}\right)$.

Peritos electricistas:

Primer grupo.- Aritmética y Álgebra, Geometría plana y del espacio y Trigonometría y Topografía.

Segundo grupo.- Física general y Química general.

Tercer grupo.- Mecánica general y Termotecnia.

Cuarto grupo.- Ampliación de Matemáticas y Geometría descriptiva.

Quinto grupo.- Magnetismo y Electricidad y Electroquímica.

Sexto grupo.- Electrotecnia.

Séptimo grupo.- Francés $\left(\mathrm{I}^{\circ}\right.$ y $2^{\circ}$ grupo).

Octavo grupo.- Geografía industrial y Economía y Legislación industrial.

Noveno grupo.- Dibujo geométrico $\left(\mathrm{I}^{\mathrm{o}}\right.$ y $2^{\circ}$ curso).

Décimo grupo.- Dibujo lineal $\left(\mathrm{I}^{\mathrm{o}}\right.$ y $2^{\mathrm{o}}$ curso).

Artículo 59.- Cuando se solicite la convalidación para esta Escuela, de las asignaturas cursadas en otros Centros de enseñanza pasará la instancia a informe de la Junta de Profesores, que en cada caso, acordará lo que proceda en vista de la extensión y carácter con que se da la enseñanza en el Centro en que esta se haya cursado.

\section{CAPÍTULO $[V I]$}

De las reválidas

Artículo 6o.- Las reválidas para los distintos Peritajes tendrán lugar en la forma que determinan los artículos 53 al 58 del Reglamento orgánico vigente.

Los derechos de examen para estos ejercicios serán los mismos que los establecidos actualmente en los Institutos generales y técnicos para la reválida del Bachillerato.

Artículo 6I.- Terminado el primer ejercicio, el Tribunal designará los aspirantes que pueden pasar al segundo. Al final de este se procederá a la calificación definitiva.

Artículo 62.- Las calificaciones en los ejercicios de reválida serán las de Sobresaliente, Aprobado y Suspenso.

Artículo 63.- Las actas de estos ejercicios se formarán por los Tribunales respectivos por duplicado, autorizándolas con las firmas de todos los vocales. Un ejemplar quedará archivado en la Escuela y el otro, acompañado del papel de pagos correspondiente y de la certificación de nacimiento del interesado, se remitirá a la Superioridad cuando se solicite la expedición del título.

Artículo 64.- La reválida para obtener el Certificado de aptitud en especialidad determinada, tendrá lugar en la forma que determina el artículo del Reglamento orgánico vigente.

Para ser admitido a estos ejercicios deberá el aspirante justificar que para en las relaciones de aptitud de las asignaturas que integran la especialidad objeto del Certificado o haber aprobado dichos estudios como alumno no oficial.

Las calificaciones de estos, serán las de Aprobado y Suspenso.

Artículo 65.- Para la expedición de los certificados será preciso que soliciten los interesados en instancia dirigida al Director de la Escuela.

\section{SECCIÓN DE ARTES Y OFICIOS}

\section{CAPÍTULO VII}

De las enseñanzas

Artículo 66.- Las enseñanzas de esta sección son las que, como de carácter general y dedicadas a la clase obrera, señala el artículo $3^{\circ}$ del RD de I6 de Diciembre de iوı。. 
Artículo 67.- Las enseñanzas propias de esta sección pueden cursarse aisladamente, sin orden de prelación.

Artículo 68.- La matrícula ordinaria estará abierta del I5 al 30 de Septiembre. La extraordinaria durante todo el mes de Octubre, para los alumnos matriculados en este tiempo no tendrán opción a premios.

Pasada la fecha del 3I de Octubre no se harán inscripciones de matrícula bajo ningún concepto.

Artículo 69.- Son propiedad de la Escuela todos los trabajos que se ejecuten en sus clases durante el curso, pero al final de esta, se reservarán aquellos más notables para la demostración de la enseñanza practicada en el Establecimiento, pudiendo devolverse a los alumnos los restantes.

Artículo 70.- A los estudios hechos libremente se les podrá dar validez académica.

\section{CAPÍTULO VIII}

De los alumnos

Artículo 7I.- El individuo que desee ingresar en esta sección deberá solicitarlo en un impreso que se le facilitará y debe reintegrar con un timbre móvil de o,Io ptas.

Acreditará haber cumplido doce años y también estar vacunado o revacunado.

Cumplidos estos requisitos, probará saber leer y escribir y las cuatro reglas fundamentales de la Aritmética.

Artículo 72.- La inscripción de las asignaturas es gratuita y se solicitará en un impreso que se facilita por los dependientes de la Escuela, pero, en cumplimiento de la ley del Timbre, se entregará un Timbre móvil de o,ı pesetas por cada asignatura.

Artículo 73.- Al hacerse la inscripción tendrán preferencia, I los alumnos que merecieron esta distinción en el año anterior, los artesanos y los dependientes de comercio; $2^{\circ}$ los hijos de artesanos y escolares; $3^{\circ}$ los estudiantes.

Artículo 74.- Cuando el número de alumnos inscritos en una asignatura sea mayor que el número de puestos disponibles en el local destinado a su enseñanza, serán llamados a ocupar los puestos los alumnos matriculados por la preferencia de inscripción y orden riguroso de inscripción expresados en el artículo anterior.

Artículo 75.- La inscripción de matrícula en una asignatura, no supone el derecho a ser admitido en la clase, sino mediante el orden establecido en los artículos anteriores.

Articulo 76.- Todo alumno queda sujeto a las obligaciones siguientes: Escuela.

I.- Al comportamiento propio de una buena educación social durante su permanencia en el local de la

2.- A la asistencia puntual a sus clases; y a justificar sus faltas dando cuenta de ellas a los Profesores de sus asignaturas.

3.- Al respeto a la autoridad de sus superiores, en cuanto a la enseñanza y disciplina académica del Establecimiento.

4.- A llevar los útiles necesarios para su labor en las clases y retirarlos después de terminado el curso.

5.- Al cuidado del material e instrumentos que se le confíen, siendo responsable de pagar el daño que intencionadamente causen.

Artículo 77.- Los castigos que pueden imponerse a los alumnos, serán los señalados en el artículo 67 del Reglamento orgánico.

Artículo 78.- Las faltas de asistencia a clase, sin una explicación favorable del alumno, serán motivo de perder el puesto que ocupe y sea necesario para otro, contándose ocho días para esta determinación.

Artículo 79.- Si el número de faltas de un alumno llegase a quince y no las hubiese justificado, perderá el derecho a hacer oposición a los premios de mérito.

Artículo 80.- Los alumnos podrán matricularse en las asignaturas que les convenga, pero no podrán repetir en aquellas cuya enseñanza se halla dividida en grupos, la parte en que hubieran obtenido certificado de aptitud en las pruebas de curso.

Artículo 8I.- Se puede solicitar permiso del Profesor de una asignatura oral, gráfica o plástica para asistir a la clase en calidad de oyente o para ocupar un puesto vacante, respectivamente, cuando no haya alumnos oficiales para ello, pero obtenido el permiso, el favorecido queda sujeto a todos los deberes de los alumnos oficialmente matriculados.

Artículo 82.- Los individuos que se inscriban como alumnos no oficiales para dar validez académica a sus estudios adquiridos privadamente, se someterán a una prueba de suficiencia. 


\section{CAPÍTULO IX}

De las pensiones y de los pensionados

Artículo 83.- Los alumnos que durante tres cursos se hayan distinguido en esta sección y deseen aprender una especialidad de la enseñanza comprendida en el grupo de las que forman las Escuelas de Artes y Oficios podrán solicitarlo de la Superioridad por conducto de la Dirección correspondiente especificando el oficio y lugar donde desean utilizar los beneficios de las pensiones a que se refiere el art. 47 del Reglamento orgánico.

Artículo 84.- A dicho efecto el Gobierno concederá cada año a los alumnos obreros y artesanos distinguidos, el número de pensiones que permita la cantidad consignada en los presupuestos.

Artículo 85.- Igualmente las Diputaciones provinciales, los Municipios, las Corporaciones y particulares que concedan pensiones a sus expensas a alguno de los alumnos de esta sección, darán conocimiento a la Subsecretaría del Ministerio de Instrucción Pública. Estos alumnos, tendrán los mismos derechos y deberes que los pensionados por el Gobierno.

Artículo 86.- Los alumnos que a su vez obtuvieran particularmente alguna pensión para cursar sus estudios en esta sección darán cuenta a la Dirección de la misma para que esta a su vez lo ponga en conocimiento de la Superioridad y se le concedan los beneficios que les correspondan como tales pensionados.

Artículo 87.- Para aspirar a las plazas de pensionado en el extranjero a que se refiere el art. 86 del Reglamento orgánico cuando aquellas hayan de recaer en alumnos de la enseñanza de Artes y Oficios, se necesitará acreditar:

Ser o haber sido alumno distinguido de esta enseñanza y tener aprobado el grupo de asignaturas y prácticas de taller si las hubiere en la Escuela correspondiente al arte $u$ oficio que desee perfeccionar.

Las pensiones se proveerán en dos turnos por concurso de mérito a propuesta del Claustro de Profesores de la Escuela y por oposición.

Los alumnos que se encuentren en condiciones podrán aspirar a ambos turnos en una misma instancia.

Artículo 88.- Tanto las pensiones por oposición como las de concurso de mérito, se anunciarán a primeros de Septiembre en tablón de edictos de la Escuela, en la Gaceta y en el Boletín oficial de la provincia, señalándose el término de un mes para la presentación de las solicitudes que se dirigirán al Director de la Escuela.

Artículo 89.- Terminado el plazo de admisión de instancias la Secretaría de la Escuela practicará las comprobaciones pertinentes a los documentos presentados por los aspirantes, que necesitarán el informe de los respectivos Profesores para mejor ilustración de la ponencia encargada de hacer la revisión y propuesta para que dictamine el Claustro.

Artículo 90.- La ponencia del concurso de mérito la formarán: el Profesor encargado de Dibujo lineal, el de término de Dibujo artístico, el de término de Modelado, el Profesor de término encargado de los talleres (si los hubiere), el Director y el Secretario de la Escuela.

Los mismos señores Profesores constituirán el Tribunal calificador de las oposiciones, y quedarán encargados de la confección de los cuestionarios y prácticas de taller necesarias en relación con las artes y oficios y especialidades solicitadas por los alumnos.

Artículo 9I.- Dichos cuestionarios y prácticas de taller no podrán exceder de las materias comprendidas en los programas de las asignaturas del grupo relacionado con la especialidad objeto de la oposición.

Artículo 92.- Los cuestionarios y ejercicios prácticos, plásticos o gráficos se darán a conocer á los opositores con ocho días de antelación.

Artículo 93.- Las oposiciones comenzarán por los ejercicios gráficos o plásticos de la enseñanza general.

Artículo 94.- Estas pensiones terminarán cuando se cumpla el plazo de duración indicado por la Superioridad o cuando el interesado estime haber dado finalidad a los estudios comprendidos en la especialidad, arte $u$ oficio solicitados; y también, cuando el alumno incurriere en las excepciones que se expresan.

Artículo 95.- Enviará, mensualmente, a la Escuela un estado justificativo de asistencia a los talleres, aulas, fábricas o establecimientos donde cursen sus estudios, así como también aquellos apuntes o notas que los pensionados consideren dignos de ser tenidos en cuenta en beneficio de la enseñanza sobre la materia que cursen.

Artículo 96.- Procurarán todos los pensionados estar en relación continua con la Dirección de la Escuela a los efectos administrativos de su pensión y de los gastos que puedan originar el envío y transporte de los trabajos producidos por aquellos.

Artículo 97.- El pensionado en la Península o en el extranjero, que faltaré a sus deberes para con la Escuela y dejare de cumplir las obligaciones impuestas en el Reglamento orgánico o en el interior, será propuesto a la Superioridad para su baja definitiva en la nómina correspondiente a la pensión.

Artículo 98.- La pérdida de curso, en cualquiera de las asignaturas o talleres que cursan los alumnos pensionados, supone también formación de expediente para la nulidad de su pensión. 


\section{CAPÍTULO X}

De las pruebas de curso

Artículo 99.- Al terminar el curso, los Profesores remitirán a la Secretaría de la Escuela una relación, firmada, de los alumnos oficiales que consideren aptos en sus respectivas asignaturas.

Artículo ioo.- Cuando un alumno oficial no figure durante dos cursos en las citadas relaciones de aptitud, deberá probar su suficiencia en el tercer curso, ante un Tribunal formado por cuatro Profesores de la Escuela, uno de ellos precisamente el de la asignatura con la presidencia del Director. Si el resultado de la prueba fuese desfavorable para el alumno, perderá el derecho a inscribirse en la misma asignatura para los cursos siguientes. Para cumplimentar esta prescripción será preciso que el alumno haya podido disponer de puesto en la clase durante el tiempo que se exige para ello.

Artículo ioI.- Las relaciones de aptitud de las clases gráficas y plásticas se formarán a la vista de los trabajos hechos durante el curso.

Artículo io2.- Las pruebas de suficiencia de los alumnos oficiales, si hubiere lugar a ello, darán principio al terminar el curso.

A continuación de estas se verificarán las de los alumnos no oficiales, previa convocatoria, y consistirán: en las clases orales, en preguntas dirigidas al alumno por un Tribunal con arreglo al programa oficial de la asignatura y durante el tiempo que estime conveniente; en las clases gráficas y plásticas en un ejercicio análogo al de los ejecutados durante el curso por los alumnos oficiales. El Tribunal podrá hacer las preguntas que crea necesarias para su juicio, acerca del trabajo ejecutado.

Artículo io3.- Del Tribunal de examen de Ingreso formará parte uno de los Profesores de ascenso, entrada, o Ayudante encargado de la enseñanza de las asignaturas de Aritmética y Geometría, o de Gramática y Caligrafía.

Artículo io4.- Los Tribunales de examen, si hay lugar a ello, se constituirán con dos Profesores de término por lo menos, pudiendo ser el tercero un Profesor de ascenso o de entrada. En todo caso, formará parte del Tribunal, el Profesor encargado o Ayudante meritorio encargado de la asignatura.

Artículo i05.- En esta sección podrán concederse premios de mérito que serán ordinarios y extraordinarios.

Además, se podrán conceder «Premios de asistencia, puntualidad y buen comportamiento» a propuesta de los Profesores respectivos.

Artículo Io6.- Los premios podrán consistir en un diploma y en una cantidad en metálico o en instrumentos, libros o herramientas del oficio o profesión a que corresponda la enseñanza, y estarán en número proporcionado con los recursos que cuente la Escuela para este objeto y con los alumnos que hayan sido declarados aptos.-

Artículo I07.- A este fin, en la última decena de Mayo podrán concederse un premio ordinario por cada veinticinco alumnos o fracción de veinticinco declarados aptos en cada asignatura, o grupo de ella para las que se hallan divididas en grupos, y en la primera quincena de Septiembre la Junta de Profesores determinará, vistos los recursos con que cuenta la Escuela y el número de premios ordinarios ya concedidos tanto en esta sección como en la Industrial, si procede o no la adjudicación de premios extraordinarios, fijando en el primer caso su número, de tal modo, que el total de premios de todas clases que puedan resultar adjudicados en ambas secciones de la Escuela, se halle en armonía con lo preceptuado en el artículo anterior.

Artículo io8.- Al fijar el número de premios extraordinarios para esta enseñanza de Artes y Oficios, la Junta de Profesores determinará también, en vista de las circunstancias si aquellos han de adjudicarse por asignaturas o grupos de asignaturas y cuales han de ser aquellos o estos.

Artículo ıо9.- Los premios de mérito ordinarios y los extraordinarios, si los hubiere, se adjudicarán por oposición. Las oposiciones a los primeros tendrán lugar en los días inmediatos a la terminación del curso, y las de los segundos, si hubiere lugar a ello, se verificarán en la segunda quincena de Septiembre.

Artículo iıo.- Los ejercicios de oposición a los premios ordinarios consistirán en las asignaturas orales en el desarrollo por escrito de un tema o resolución de problema, referente al programa oficial de la asignatura. En las clases gráficas y plásticas en la ejecución, dentro del grupo objeto de la oposición, de un trabajo igual o semejante a los que se hayan practicado en la clase durante el curso.

Los ejercicios de oposición a los premios extraordinarios los determinarán en cada caso los Tribunales correspondientes.

Artículo inI.- Los Tribunales de oposición a los premios ordinarios se constituirán en la forma que señala el artículo I04 para los de exámenes de asignaturas cuando los hubiere y serán nombrados por el Director de acuerdo con la Junta de Profesores.

Los Tribunales que hayan de juzgar los ejercicios a premios extraordinarios serán los que acuerde el Claustro de Profesores a propuesta del Director.

Artículo iı2.- Durante los ejercicios de oposición a toda clase de premios, no serán corregidos por nadie los trabajos de los alumnos, bajo pena de quedar estos excluidos de la oposición. 


\section{CAPÍTULO XI}

\section{Del Director}

Artículo iı3.- Además de los derechos y deberes atribuidos al Director de la Escuela por el artículo $7^{\circ}$ del Real decreto de i6 de Diciembre de I9ı。, corresponde al ejercicio de este cargo:

(a) Entenderse directamente con los Centros, corporaciones y particulares que tengan relaciones oficiales con la Escuela.

(b) Encargar a los Profesores trabajos o informes relacionados a la administración o régimen de la enseñanza o relativos al personal de la Escuela y nombrar comisiones que dictaminen en asuntos de aquella índole, ya para ilustración de puntos determinados cuya resolución es de su autoridad, ya para someter su resolución en consulta a la Junta de Profesores.

(c) Disponer la realización de toda clase de gastos correspondientes a la consignación del material, sometiendo las cuentas trimestrales al examen de la Junta de Profesores, en conformidad con lo dispuesto en el párrafo $4^{\circ}$ del artículo i6 del Reglamento orgánico.

(d) Representar a la Escuela en los actos oficiales.

(e) Determinar los días de vacaciones, que no podrán exceder de los preceptuados en los Reglamentos generales vigentes.

(f) Conceder hasta quince días de licencia al personal de todas clases a sus órdenes, solo por una vez durante el curso.

(g) Amonestar al Profesor que observara manifiesta negligencia, y si esta fuese reiterada dar cuenta a la Superioridad.

Artículo II4.- El Director, como jefe de todos los talleres, museos, gabinetes y laboratorios de la Escuela, podrá delegar las atribuciones que por este concepto le corresponden en Profesores de número de enseñanzas afines a los servicios afectos a estas dependencias, en los términos previstos en el artículo I5 del Real decreto orgánico vigente.

Artículo ir5.- En los donativos y en las donaciones de carácter permanente o transitorio, estatuidos a favor de las enseñanzas o alumnos de la Escuela en que ejerza el patronato por derecho de las mismas, le corresponden la inspección y constante vigilancia del cumplimiento de los deseos del fundador, dentro de las condiciones que se impongan por el mismo y de acuerdo con las autoridades superiores.

\section{CAPÍTULO XII}

De los Profesores de término

Artículo ir6.- Los Profesores de término tienen los deberes y atribuciones siguientes:

(a) Formar el programa de su asignatura y someterle a la aprobación de la Junta de Profesores, en cuanto se refiere a su extensión y límites y a las relaciones mutuas con las demás enseñanzas afines.

(b) Procurar con todo empeño que la extensión de sus programas y la distribución por lecciones, se acomoden a las exigencias de la práctica, a fin de que pueda aquel desarrollarse por completo en el curso. El Director podrá prolongar el curso hasta la terminación de los programas, dando cuenta a la Superioridad.

(c) Comunicar al Director los desperfectos y faltas que ocurran en el material y menaje de las clases.

(d) Asistir a las Juntas de Profesores, participando por escrito al Director, en su caso, el motivo que le impidiese cumplir con esta obligación.

(e) Velar como único responsable de la enseñanza porque los Auxiliares y Ayudantes de su clase, cumplan estrictamente los deberes de su cargo y realicen fielmente el programa en las lecciones o comisiones que se les encomiende.

(f) Dar cuenta el Director de las faltas de asistencia de los empleados que asisten a sus clases.

(g) Evacuar los informes y dictámenes que se les pidieren por el Director de la Escuela, y formar parte de las comisiones para las que fuere designado por la misma autoridad o por la Junta de Profesores.

(h) Formar parte de los tribunales de examen y de los de oposiciones a premios para los que fuere nombrado por el Director.

(i) Dirigir las prácticas de taller que fueran de su competencia por corresponder a la asignatura de su cargo, de acuerdo con el jefe de taller y con la aquiescencia del Director.

(j) Servir, cuando fuere designado para ello, el cargo de Habilitado, siempre que no haya causa justa que lo impida.

(k) Proponer a la Dirección todo cuanto creyere conveniente al bien y prosperidad de la enseñanza. 
Artículo II7.- En caso de enfermedad, deberá el Profesor dar cuenta oportunamente al Director, para que este prevea quien haya de sustituirle en las lecciones a que se vea obligado a faltar.

Artículo iı8.- Todo el material de enseñanza de la Escuela estará inventariado, quedando bajo la inmediata inspección del Profesor respectivo, y si fueren varios, de la persona que de común acuerdo determinen.

Artículo iI9.- Durante el período de vacaciones podrán los Profesores ausentarse de Logroño, participando al Director de la Escuela el sitio donde hayan de residir, debiendo volver a prestar sus servicios dentro de la segunda quincena del mes de Septiembre, si antes no fueran necesarios sus indicados servicios.

Artículo I20.- Los Profesores de término usarán en los actos oficiales la medalla correspondiente.

Artículo I2I.- El Profesor que se hiciere notar por su asiduidad y resultados especiales de la enseñanza, por haber dado conferencias públicas en la Escuela, por haber inventado un aparato o herramienta de aplicación a los oficios o artes industriales o por haber escrito o ejecutado una obra de utilidad reconocida por la Junta de Profesores, será propuesto por el Director a la Superioridad oyendo a la Junta de Profesores, para una recompensa en armonía con el merecimiento adquirido.

\section{CAPÍTULO XIII}

De la Junta de Profesores

Artículo i22.- La Junta de Profesores se constituirá con arreglo a lo dispuesto en el artículo i5 del Reglamento orgánico vigente.

Artículo I23.- La Junta general será convocada por el Director de la Escuela, bien por iniciativa propia o bien a instancia escrita y firmada por la tercera parte, lo menos, de los vocales y en la cual conste el motivo de la convocatoria. Las citaciones se harán con veinticuatro horas por lo menos de anticipación para el debido conocimiento de la orden del día, salvo casos urgentes.

Artículo i24.- Entenderán en los asuntos que determina el Reglamento orgánico y este interior y en los que le fueren sometidos por la Superioridad o la Dirección de la Escuela.

Artículo I25.- Las sesiones comprenderán: I $^{\circ}$ lectura, discusión y aprobación del acta anterior.- $2^{\circ}$ cuenta de los asuntos de despacho ordinario que a juicio del Director de la Escuela deban ser del conocimiento de la Junta.- $3^{\circ}$ despacho de los que forman la orden del día.- $4^{\circ}$ los que puedan ser sometidos al juicio de la Junta por cualquiera de sus vocales.

Artículo I26.- La asistencia a las Juntas es obligatoria para los Profesores y solo se podrán excusar por causa justificada a juicio del Director. De todos modos las ausencias se apreciaran en iguales términos que las faltas de asistencia a clase.

Artículo I27.- La Junta de Profesores gozará de todos los derechos y preeminencias que otorga a estas Corporaciones la Legislación general vigente.

Artículo i28.- Para que el Director de la Escuela pueda evacuar el informe propuesta a que se refiere el artículo I4 del Reglamento de I6 de Diciembre de I9IO, con el mayor prestigio en pro del interesado, se procederá en los términos siguientes:

El Director convocará por escrito a la Junta de Profesores en pleno para este solo asunto con la anticipación conveniente al efecto de que puedan cambiarse impresiones entre los vocales en asunto de tal importancia.

Reunida la Junta, se procederá en primer término a decidir en votación por bolas si ha lugar por el curso corriente a la propuesta de premio de 500 pesetas reglamentario.

Si resultase acuerdo afirmativo se votará por papeletas el nombre del candidato. En ambos casos se ha de obtener mayoría absoluta de sufragios.

\section{CAPÍTULO XIV}

\section{De la Junta Económica}

Artículo I29.- La Junta económica de esta Escuela se constituirá conforme prescribe el artículo 36 del Reglamento orgánico, con el Director, el Secretario, el Habilitado y dos vocales elegidos por la Junta de Profesores.

Cuando alguno de los vocales natos lo sea por más de un concepto, se completará la Junta con vocales electivos hasta el número de cinco.

Artículo I30.- La Junta económica se reunirá una vez, por lo menos, cada trimestre.

Artículo 13I.- Corresponde a esta Junta:

I $^{\circ}$. Examinar las peticiones hechas a la Dirección de la Escuela y acordar la adquisición de material de enseñanza en vista de la cantidad disponible para este objeto. 
$2^{\circ}$. Distribuir la cantidad recaudada por derechos de prácticas. De esta distribución se dará cuenta al Rectorado, a quien se remitirán los justificantes de inversión de los expresados derechos para su aprobación, debiendo archivarse en la Secretaría de la Escuela.

$3^{\circ}$. Intervenir en todo lo concerniente a la distribución de donaciones, pensiones y premios en metálico.

$4^{\circ}$. Informar en cuantos asuntos económicos considere oportuno el Director de la Escuela.

Artículo i32.- Los acuerdos se tomarán, si fuere preciso, por mayoría de votos. De estos acuerdos, se dará cuenta en la Junta de Profesores.

\section{CAPÍTULO XV}

De los Profesores de ascenso y de entrada

Artículo 133.- Es obligación del Profesorado auxiliar:

(a) Cumplir las órdenes de los Profesores de término a cuyas clases estén destinados, sin perjuicio de acudir en alzada al Director después de cumplidas, si creyeren lastimados sus derechos.

(b) Acudir diariamente a las clases para tener preparado el material, cuidando de que no haya entorpecimiento alguno al comenzar las lecciones.

(c) Velar porque todo el material de enseñanza se halle en el más perfecto estado de aseo y conservación, dando cuenta al Profesor de la asignatura de todo desperfecto que observe y cuidando de que los dependientes destinados al servicio de aquel departamento cumplan con todo esmero sus deberes.

(d) Formar el correspondiente inventario del referido material tomando nota de las altas y bajas que ocurran y dando cuenta de ellas al Profesor respectivo. clase.

(e) Poner en conocimiento del Profesor toda falta de orden y disciplina que cometieren los alumnos de la

(f) Asistir a las prácticas que les correspondan y tomar parte activa en ellas bajo las órdenes del Profesor, dirigiendo aquellas que le correspondan.

(g) Realizar estrictamente el programa de la asignatura, si estuviesen encargados de algún grupo de alumnos en las enseñanzas orales o de la corrección de las gráficas o prácticas.

(h) Preparar los aparatos y experimentos en las clases orales y tomar parte activa en las manipulaciones que la lección exija, siempre que el Profesor lo dispusiere.

(i) Auxiliar al Profesor en los trabajos que reclamen los exámenes y ejercicios de oposición.

(j) Servir el cargo de Habilitado cuando para ello fueren designados, siempre que no haya causa justa que lo impida.

Artículo 134.- En ausencias o enfermedades el Auxiliar adscrito a la asignatura sustituirá al Profesor.

Artículo I35. Se entiende aplicable a los Auxiliares lo establecido en el artículo de este Reglamento respecto a recompensas por servicios extraordinarios.

Artículo I36.- Los Ayudantes Meritorios, durante la época en que prestan servicio, tendrán las mismas obligaciones y consideraciones que los Profesores de entrada.

\section{CAPÍTULO XVI}

\section{Del Secretario de la Escuela}

Artículo 137.- Los deberes y atribuciones del Secretario son los siguientes:

I $^{\circ}$ Dar cuenta al Director de los asuntos que ocurran, despachando con el mismo los expedientes de toda clase tramitados por la Oficina de su cargo e instruidos bajo su dirección y con su dictamen.

$2^{\circ}$ Redactar las comunicaciones y documentos oficiales que no estime conveniente encargar a los empleados de Secretaría, y rubricar los oficios que haya de firmar el Director, siendo responsable de su redacción y de conformidad con los acuerdos que realizan.

$3^{\circ}$ Dirigir las operaciones de oficina relativas a matrículas y exámenes.

$4^{\circ}$ Pedir y despachar las acordadas para compulsa de documentos presentados.

$5^{\circ}$ Expedir, con el $\mathrm{V}^{\circ} \mathrm{B}^{\circ}$ del Director, los Diplomas, las certificaciones de estudios y de los documentos que se custodian en el Archivo, percibiendo por su expedición los mismos derechos que actualmente están establecidos para los Institutos generales y técnicos, en lo que se refiere a enseñanza industrial.

$6^{\circ}$ Redactar las actas de las Juntas de Profesores, Juntas económicas y Consejo de disciplina. 
$7^{\circ}$ Como Jefe de la Secretaría y su Archivo, cuidará, bajo su responsabilidad, del buen régimen de estas dependencias y de la conservación metódica de todos los documentos puestos a su cuidado haciendo la distribución de asuntos entre los empleados administrativos a sus órdenes.

Cuidar de que lleven con esmero y precisión los registros de entrada y salida, copiadores de actas y de órdenes (los de estas por separado las particulares de la Escuela y las de carácter general) y cuantos libros y registros se consideren necesarios al mejor régimen administrativo y académico.

$9^{\circ}$ Formar el expediente personal de cada uno de los Profesores y Empleados de todas clases y de los alumnos de la Escuela, haciendo constar en ellos las hojas de servicios de los que figuran en la plantilla y en todos cuantos incidentes se refieran a su estancia en el Establecimiento y que formen el historial del interesado.

Artículo I38.- Como Bibliotecario del Establecimiento tendrá un catálogo ordenado por materias y por orden alfabético de los libros y colecciones de láminas propiedad de la Escuela.

Prestará, durante un tiempo prudencial, los libros y obras que le pidan los Profesores y dependientes de la Escuela, mediante recibo firmado por los mismos y en todo caso renovable al principio de cada curso.

\section{CAPÍTULO XVII}

Del Habilitado y de la contabilidad

Artículo I39.- El Habilitado de la Escuela desempeñará las funciones que le encomiendan el Real decreto y Reglamento de I6 de Diciembre de igio. Desempeñará este cargo un Profesor elegido en votación hecha entre los Profesores y empleados de planta de la Secretaría.

Artículo I40.- La votación será secreta y tendrá lugar en un día señalado al efecto, dentro del último mes del año económico. Cada papeleta deberá contener dos nombres, uno para el Habilitado y otro para el Suplente, entendiéndose, de no especificarlo la candidatura, que el nombre que figure el primero en la papeleta es el del Habilitado.

El Escrutinio se hará por el Secretario de la Escuela que verificará el resultado, elevándose la certificación a la Subsecretaría del Ministerio.

Artículo I4I.- El Habilitado del personal lo será también del material, tanto ordinario como de oficina.

Artículo I42.- El Habilitado realizará los libramientos que por la Ordenación de Pagos del Ministerio de Instrucción Pública y Bellas Artes, se expidan a su favor en la forma prescrita por la Superioridad. Los pagos para atenciones del material, se harán mediante recibos, facturas o cuentas, en las que se hará constar la ejecución de servicio y el páguese del Director de la Escuela.

Al efecto, todo servicio ha de ser autorizado por el Director previa demostración de su necesidad por el Profesor y Jefe de la dependencia a que corresponda, que deberá presentar el presupuesto o fijar el coste aproximado. El Director deberá consultar con el Habilitado si hay fondos o créditos bastantes para la realización del servicio.

Una vez realizado éste, presentará por duplicado, en Secretaría, el recibo, factura, relación o cuenta, y pasará el documento a la firma del Director. Con el $V^{\circ} B^{\circ}$ de éste, el Habilitado satisfará su importe y guardará el documento y su duplicado hasta el momento de rendir cuentas, que será trimestralmente.

Formada así la cuenta de los gastos de material ordinario y su comprobación en la Secretaría, se someterá al examen de la Junta de Profesores, elevándose después a la aprobación de la Subsecretaría del Ministerio.

Artículo I42.- Formadas las nóminas del personal de cada año, para ser examinadas en Secretaría y cumplido este requisito, se autorizarán con el $\mathrm{V}^{\circ} \mathrm{B}^{\circ}$ del Director, según está prevenido.

Artículo I44.- La inversión del material de oficina se regirá por las disposiciones contenidas en el Real decreto de 24 de octubre de I884, en armonía con el de 3i de Mayo de I88I, ejerciendo el Secretario las funciones de Interventor. El Director de la Escuela aprobará estas cuentas y ordenará que se archiven en la Secretaría por trimestres.

Artículo I45.- El Habilitado dará conocimiento mensualmente al Director del estado de fondos.

\section{CAPÍTULO XVIII}

De los empleados de Secretaría

Artículo I46.- Los deberes del Oficial de Secretaría son:

$\mathrm{I}^{\circ}$ Auxiliar al Secretario en el servicio del Archivo.

$2^{\circ}$ Extractar las solicitudes en curso, uniendo a ella los antecedentes, si los hubiera, y consignar su dictamen bajo su firma a continuación del extracto, poniéndolas al despacho del Secretario teniendo muy en cuenta, tratándose de personal, que no se consentirá bajo ningún pretexto el que una misma persona tenga dos o más expedientes, pues en uno solo han de hacerse constar todas las pretensiones y vicisitudes del interesado. 
$3^{\circ}$ Redactar las minutas de las órdenes y comunicaciones cuando el Director o Secretario no se reserven hacerlo en conformidad con los acuerdos tomados o instrucciones recibidas, sometiéndolas a la corrección y rúbrica del Secretario.

$4^{\circ}$ Confrontar con las minutas las comunicaciones puestas en limpio por los escribientes, siendo responsable de su conformidad con el original.

Artículo I47.- El Oficial de Secretaría será responsable ante el Secretario de todos los trabajos de la oficina.

Artículo I48.- Los deberes de los escribientes consisten en poner en limpio todos los trabajos que se les encomienden por el Director, Secretario y Oficial de Secretaría, llevar los registros generales de entrada, tramitación y salida; los copiadores de órdenes particulares y generales, el cierre y servicio de habilitación; ordenar los expedientes en curso y los que hayan de archivarse y entender en todo lo referente a matrículas y exámenes bajo las órdenes de sus superiores.

\section{CAPÍTULO XIX}

\section{Del Vaciador}

Artículo I49.- El cargo de Vaciador podrá ser propuesto a la Superioridad por el Director de la Escuela, oyendo a la Junta de Profesores sobre su conveniencia.

Artículo I50.- La propuesta se referirá a persona conocida con anterioridad por sus trabajos del género que conviene a este servicio.

Artículo I5I.- Deberá tener su taller especial dentro de la Escuela o en su defecto utilizar el material fijo de las clases de Modelado y Vaciado. En este último caso el Profesor de la misma lo utilizará para ella debidamente.

Articulo I52.- Las obligaciones del Vaciador serán:

(a) Restaurar y reproducir los modelos de yeso que le ordene el Director, a propuesta de los Profesores de la sección de Artes y Oficios.

(b) Recibir por inventario el material fijo y las herramientas especiales del taller para su guarda y con su responsabilidad.

(c) Dar recibos de los materiales y primeras materias que se le entreguen y justificar al Director del empleo de las mismas.

(d) Llevar un libro donde consten los trabajos que ejecute y entregue al Director.

(e) Pedir autorización al Director para la adquisición de material y para utilizar los servicios de los mozos o contratar un auxiliar en trabajos especiales.

\section{CAPÍTULO XX}

Del Conservador del material científico

Artículo I53.- El conservador de los instrumentos y del material científico, será inmediatamente el responsable de todo aquello que se le entregue para su cuidado y conservación por los Profesores correspondientes a las clases que lo utilicen.

Estará siempre conocedor del estado de uso en que se halle y deberá proponer a sus jefes respectivos las reparaciones que, a su juicio, convengan para su mejor conservación.

No entregará objeto alguno de los que tenga a su cuidado, sin orden escrita del Director.

\section{CAPÍTULO XXI}

\section{Del Conserje}

Artículo I54.- Además de los artículos 69 y 70 del Reglamento orgánico, se consideran derechos y deberes del conserje los siguientes:

(I) Habitar en el edificio que ocupa la Escuela y responder con su constante vigilancia de la custodia de cuanto en ella se encierra. El Director dispondrá las horas diarias en que ha de ser reemplazado de este servicio.

(2) Ordenar y distribuir, con la mayor equidad, entre los mozos el trabajo diario de la limpieza e higiene del Establecimiento.

(3) Encargarse de cumplir y hacer cumplir a los citados dependientes a las órdenes del Director y Profesores que tengan relación con el servicio y disciplina de la Escuela.

(4) Recibir del Habilitado y por inventario el mobiliario y enseres puestos a su cuidado y llevar el alta y baja que vayan experimentando, con nota del motivo de su variación. 
(5) Velar por el orden de los alumnos dentro de las galerías del Establecimiento, amonestándoles con la mayor consideración por sus faltas o dando cuenta al Director de las que por su calidad, merezcan serle conocidas.

(6) Hacer requisa general de cierre de las luces y contadores de gas, cuando se hayan terminado las clases.

Artículo I55.- En ausencia y enfermedad del conserje, el bedel le sustituirá en todo lo referente al servicio de aquél.

Del Bedel

Artículo 156.- Las obligaciones especiales de este dependiente serán las siguientes:

(I) Avisar con exactitud la hora de entrada y salida en las clases.

(2) Dar parte diario de la asistencia de los Profesores.

(3) Auxiliar al Conserje en la vigilancia y disciplina de los alumnos, dentro de las galerías durante las horas de clase.

(4) Asistir al Establecimiento durante las horas de Oficina.

De los Mozos de oficio

Artículo 157.- Las obligaciones de los Mozos de oficio serán las siguientes:

(I) Cumplir las órdenes de sus superiores en general y del conserje, como jefe inmediato, en cuanto al servicio de la Escuela sea necesario.

(2) Hacer la limpieza del Edificio a las horas que no haya enseñanza en él.

(3) Atender al aseo de los locales y de cuantos objetos se custodian en ellos, dando cuenta al conserje de los desperfectos de toda clase que observen.

(4) Explicar satisfactoriamente los desperfectos que ocurran durante su servicio.

(5) Asistir a las horas de enseñanza para vigilar el orden de los alumnos en las clases más numerosas, si los Profesores estiman más conveniente su necesidad.

(6) Encender y apagar el alumbrado de las clases.

Artículo I58.- En ningún caso ni bajo ningún pretexto permitirán el Conserje, Bedel o Mozos de servicio que se saque material alguno de la Escuela, aunque sea del que no está bajo su inmediata custodia ni responsabilidad, sin permiso escrito del Director, que ha de exhibirse para ello, excepto los libros, de los que el Bibliotecario exige recibo.

Aprobado este Reglamento en Junta de Profesores celebrada en 30 de Septiembre de i9ı2. Modificado el artículo 58 en la forma en que se halla en Junta de Profesores de la Escuela en 2i de Febrero de i9i3.

$\mathrm{V}^{\circ} \mathrm{B}^{\mathrm{o}}$

El Director

Manuel Pérez Ordoyo»
El Secretario,

Rupero G. Segura 